\title{
Hacia un sistema de filiación que consagre facultades y derechos específicos para el padre no custodio*
}

\author{
Rodrigo Barcia Lebmann**
}

\section{RESUMEN}

El presente texto critica el modo en que se asigna el cuidado personal en nuestro Derecho, pero sobre todo articula, a partir del Derecho comparado, un sistema de facultades y derechos para el padre no custodio respetuoso del principio de la igualdad de los padres, que estaría subsumido dentro del principio del interés superior del niño, comparando el sistema chileno antes y después de la reciente Reforma del 2013.

Derecho de familia - cuidado personal - filiación

\section{Towards a system of parenthood that institutes specific powers and rights for the non-custodial parent}

\begin{abstract}
This paper criticizes the way in which our legal system assigns custody of children. Mostly articulated from sources of comparative law, it presents a system of powers and rights for the non-custodial parent, which is respectful of the principle of equality of parents, which in turn is comprised in the principle of the best interests of the child. The Chilean system is analysed concerning the changes introduced by the recent reform of 2013.
\end{abstract}

Family law - Custody - parenthood

* Le agradezco a Carolina Riveros su valiosa ayuda en la discusión del presente texto.

** Abogado, Doctor en Derecho, Profesor Investigador de la Facultad de Derecho de la Universidad Finis Terrae, Santiago de Chile. Correo electrónico: rbarcia@uft.cl.

Artículo recibido el 30 de marzo de 2013 y aceptado para su publicación por el Comité Editorial el 28 de octubre de 2013.

ABREVIATURAS: BGB = Bürgerliches Gesetzbuch [Código Civil alemán]; CC = Código Civil; CCCh = Código Civil chileno; $\mathrm{CCE}=$ Código Civil español; Code = Código Civil Francés; Codice Civile = Código Civil italiano; $\mathrm{CIADH}=$ Corte Interamericana de Derechos; CDN = Convención de Naciones Unidas sobre Derechos del Niño (de 27 de noviembre de 1990); LF = Ley de Filiación (Ley No 19.585/1998); LMC = Ley de Matrimonio Civil (Ley No 19.947/2004); LTF = Ley de Tribunales de Familia (Ley N ${ }^{\circ}$ 19.968/2004); LPG = Ley de Participación en los Gananciales (Ley N N $^{\circ}$ 9.335/1994); LPM = Ley de Protección de Menores (Ley N ${ }^{\circ}$ 16.618/2000); LVIF = Ley de Violencia Intrafamiliar (Ley No 20.066/2005); NU = Naciones Unidas; $\mathrm{TC}=$ Tribunal Constitucional; $\mathrm{TEDH}=$ Tribunal Europeo de Derechos Humanos; $\mathrm{TF}=$ Tribunales de Familia; VIF = Violencia Intrafamiliar. 


\section{INTRODUCCIÓN}

$\mathrm{E}$ 1 presente artículo tiene como objetivo contraponer el sistema de asignación unilateral de facultades y derechos de filiación con los sistemas del Derecho Comparado que en el pasado han optado por esta clase de sistema. Ello es especialmente relevante a causa de la reciente Reforma, introducida al cuidado personal por la Ley $\mathrm{N}^{\circ}$ 20.680, publicada en el Diario Oficial el 21 de junio del 2013. Esta Reforma establece un sistema de facultades y derechos conjuntos e indistintos para los padres separados que no acuerden el cuidado conjunto. A este respecto, se analizará la importancia que en estos Derechos ha tenido el principio del interés superior del niño y cómo ha influido en ellos el principio de la igualdad de los padres. El principio de la igualdad de los padres ha sido una manifestación más del principio rector del Derecho de la Infancia, como lo es el principio del interés superior del niño. Esta absorción del principio de la igualdad de los padres por el interés superior no se dio de forma violenta o repentina en el Derecho comparado, sino que provino de la natural evolución de los sistemas de asignación exclusiva de facultades y derechos de filiación. Es esta primera etapa en la evolución del Derecho comparado la que se analiza en este trabajo. Ella es de una importancia vital por cuanto recién los últimos años y de forma muy lenta el Derecho chileno ha optado tímidamente por adoptar un sistema de asignación del cuidado personal a uno de los padres, según el interés superior del niño. De este modo nuestro Derecho ha ido dejando parcialmente de lado la regla de la preferencia materna mediante sendos fallos de la CS y del TC (regla que, como ser verá, sería declarada inconstitucional por el Tribunal Constitucional y por la propia reforma reseñada precedentemente), y se ha optado por la definitiva expulsión de la regla de la preferencia materna. Antes de la Reforma del 2013 se generaba una concentración de facultades en la madre, que era incompatible con el principio de igualdad de los padres, solución que además atentaba contra el principio del interés superior del niño.

Este artículo más que tratar los criterios de asignación de las facultades y derechos de filiación -específicamente en los ordenamientos jurídicos, que, como el nuestro, asignan derechos y facultades de forma exclusiva-, pone su acento en las facultades y derechos del padre no custodio como forma de aplicación de los principios de interés superior de los niños e igualdad de los padres. En este sentido, el trabajo permite justificar la Reforma del 2013, que se centra en las facultades y derechos que corresponden al padre no custodio y en las facultades conjuntas que tienen los padres con relación a los hijos, cualquiera que sea su relación personal. A su vez, la presente investigación no trata en detalle estas facultades y derechos, por cuanto lo que se debe destacar es que los diferentes ordenamientos jurídicos, a través de la ley y/o los tribunales, han establecido facultades y derechos para el padre no custodio, como contrapeso a las facultades y derechos exclusivamente asignados a uno de los padres. Esta técnica será fundamental para poder determinar el alcance de la Reforma del 2013.

En definitiva, este artículo se estructura para estos efectos en las siguientes partes: (i) la presente introducción; (ii) los ordenamientos jurídicos que asignaban de forma indistinta o exclusiva la patria potestad, el cuidado, la responsabilidad o la autoridad 
parental, y las facultades y los derechos de control y apoyo del padre excluido; (iii) el sistema chileno de asignación del cuidado personal y autoridad parental y de facultades y derechos del padre no custodio antes de la Reforma del 2013; (iv) referencia a la Reforma al cuidado personal en materia de asignación de facultades y derechos de filiación para el padre custodio y no custodio y a la Ley $\mathrm{N}^{\circ} 20.680$ y (v) las principales conclusiones del presente trabajo.

\section{LOS ORDENAMIENTOS JURÍDICOS QUE ASIGNABAN DE FORMA INDISTINTA O EXCLUSIVA LA PATRIA POTESTAD, EL CUIDADO, LA RESPONSABILIDAD O LA AUTORIDAD PARENTAL, Y LAS FACULTADES Y LOS DERECHOS DE CONTROL Y APOYO DEL PADRE EXCLUIDO}

En cuanto a los sistemas de Derecho comparado, en torno a la asignación de facultades y derechos de filiación, es preciso efectuar dos interrogantes. La primera es: ¿la asignación de facultades y derechos de filiación, en sí misma, se hace según el principio del interés superior del niño? y la segunda es: si una vez efectuada la asignación, de acuerdo con dicho principio, ¿su ejercicio se hace de acuerdo al interés superior del niño? Para este efecto es menester tener presente que el principio del interés superior del niño es relevante en las siguientes dos dimensiones: el desarrollo de los derechos del niño y adolescente como seres independientes y conscientes (principio del ejercicio progresivo de los derechos de la infancia), por una parte, y su protección como un ser humano en formación (principio de protección de la infancia), por la otra ${ }^{1}$.

${ }^{1}$ El desarrollo de los derechos de la infancia, a través fundamentalmente de la CDN, es lo que ha dado lugar al denominado Derecho de la Infancia y de la Adolescencia, que se contrapone con el denominado Derecho de Menores, que tenía un fuerte sustento asistencial. Esta distinción es muy relevante por cuanto se mantiene hasta hoy. Así, en los casos en que el niño o adolescente corre peligro, su ámbito de autonomía disminuye. El juez debe, frente a estos supuestos, aplicar las medidas cautelares o de protección de la infancia, como si un niño se opone a que se le realice una transfusión de sangre en atención a sus creencias. En estos casos se aplica el interés superior como principio de protección de la infancia, pero no como una forma de desarrollar la personalidad del niño o del adolescente.

De este modo, por citar algunos trabajos, se puede analizar al principio del interés superior del niño como derecho de protección de la infancia en: Varas, Juan Andrés, "Decisiones vitales y representación parental: Fundamento y límites”, en: Estudios Derecho Civil V, Jornadas Nacionales de Derecho Civil, Concepción, AbeledoPerrot, LegalPublishing, Santiago de Chile, 2009, pp. 337-356; y Vivanco, Ángela, "Negativa de un menor de edad y de su familia a que este reciba una terapia desproporcionada o con pocas garantías de efectividad. apelación de medida de protección otorgada por la jueza de Familia de Valdivia. Sentencia de la I. Corte de Apelaciones de Valdivia, de 14 de mayo de 2009", en: Revista Chilena de Derecho, vol. $36 \mathrm{~N}^{\circ}$ 2, pp. 399-440 [2009].

Sin perjuicio de lo anterior, un análisis más profundo de estas dos acepciones del interés superior del niño se pueden ver en: Barcia, Rodrigo, "Principios en los que se inspiran el Derecho de familia -en especial del matrimonio y de la infancia", en: Nos Ad Justitiam Esse Natos, Libro de Homenaje a la Escuela de Derecho de la Universidad de Valparaíso en el Centenario de su fundación (1911-2011), dirigido por Luis Guzmán, 2011, pp. 21 a 40. 
La propuesta de trabajo precedente -que se basa en las dos preguntas señaladas en el párrafo anterior- se sustenta en el Derecho comparado ${ }^{2}$, y permite apreciar de forma más nítida la relación entre los principios del interés superior del niño y la igualdad de los padres. Por ello, dicho planteamiento obliga a justificar la distinción entre la asignación de las facultades y derechos en sí misma -constitutiva si se quiere- y su ejercicio. Esta distinción es relevante en los sistemas jurídicos que han optado por establecer sistemas de asignación de facultades y derechos de cuidado, patria potestad, autoridad parental o responsabilidad parental exclusivo a favor de uno de los padres, como el nuestro, después de la Reforma del $2013^{3}$. Estos sistemas suelen establecer reglas de asignación legal supletoria, y de asignación judicial. Asumiendo que la regla óptima, en un sistema de asignación unilateral o exclusivo, es el interés superior del niño, el cuidado personal se otorgará al padre con mayores habilidades parentales. Sin embargo, si se favorece una regla de asignación de facultades y derechos exclusivos a uno de los padres, según el interés superior del niño, paradójicamente se puede estar violando dicho principio. Por cuanto un sistema de esta clase ignora los aportes que puede realizar a la vida del niño o adolescente el padre excluido de la asignación, aun cuando sus habilidades parentales sean menores. La relación entre ambos principios, a este respecto, se hace evidente, por cuanto el principio de igualdad de los padres desarrolla la personalidad del niño y del adolescente $^{4}$. En efecto, una regla de asignación exclusiva, como la precedente, por sí sola violenta el principio del interés superior del niño, sobre todo si el Derecho no concede una serie de facultades y derechos al padre porque no se le concede la asignación exclusiva ${ }^{5}$. Por ello precisamente es que los ordenamientos jurídicos de asignación de facultades y derechos de filiación, a uno de los padres, van derivando indefectiblemente hacia sistemas en que las facultades y derechos son conjuntos. El proceso comienza, en los sistemas de asignación unilateral, en la medida que se reconocen facultades y derechos para el padre no custodio, como las facultades y deberes de vigilancia y control; ayuda y auxilio y educación restringida. Entre nosotros, la opción adoptada por la Reforma del 2013 presenta dos mecanismos de acercamiento del padre no custodio: (i) la corresponsabilidad, que es necesariamente conjunta de acuerdo con el actual artículo 224, y (ii) la relación directa y regular del padre no custodio con el hijo, que tiene un contenido

${ }^{2}$ De este sistema de contrapesos nos da cuenta Castán Vásquez ya en el año 1987, indicándonos que ya era aplicado desde la década de los setenta en Portugal, Francia e Italia.

Castán, J. M., "La patria potestad sobre los hijos nacidos fuera del matrimonio", en Revista de Derecho Privado, 1987, p. 200.

${ }^{3}$ El presente trabajo se centra fuertemente en el Derecho comparado, por lo que cuando se utiliza la expresión patria potestad, respecto de otros ordenamientos jurídicos, ella es comprensiva del conjunto de facultades y derechos, por una parte, y de deberes y obligaciones, por la otra, que los padres tienen con relación a sus hijos. Así, solo cuando dicha expresión se utiliza en el Derecho chileno, ella se restringe solo a los aspectos patrimoniales.

${ }^{4}$ Evidentemente que en los casos de conflicto, como si la relación de uno de los padres daña al niño, prima el principio del interés superior.

${ }^{5}$ No me refiero a los deberes y obligaciones propiamente tales, por cuanto ellos, en la mayoría de los sistemas jurídicos, están claramente establecidos, y son naturalmente conjuntos. 
que naturalmente se irá expandiendo, como se aprecia de la simple lectura de los nuevos artículos 229 y 229-2 del CCCh.

En el fondo los sistemas de asignación de facultades y derechos de filiación, provenientes del Derecho comparado, aplican el interés superior conjuntamente con el principio de la igualdad o no discriminación de los padres. Ello ha llevado a que en muchos ordenamientos jurídicos se hayan abandonado los sistemas que asignan facultades y derechos que tienen relación con el cuidado personal de forma exclusiva a uno de los padres. Estos últimos sistemas, a su vez, establecen -vía legal o jurisprudencial- facultades y derechos de control y apoyo respecto del padre no custodio al custodio. Estos sistemas se analizan en el presente trabajo, ya que desde la reforma nuestro ordenamiento jurídico se encuentra inserto en un sistema de esta clase que debería transitar hacia un sistema de facultades y derechos conjuntos. Así, el Derecho comparado, a partir de los sistemas precedentes, ha evolucionado hacia sistemas que establecen facultades y derechos compartidos ${ }^{6}$.

Una gran cantidad de ordenamientos jurídicos, sobre todo en el pasado, después de asignar las facultades y derechos de filiación a uno de los padres, han establecido una serie de facultades y derechos respecto del padre no custodio. Esta asignación de facultades y derechos de filiación de paternidad se desarrolló en Francia, a través de la ley de 4 de junio de 1970; en Italia, de acuerdo con las leyes de 14 de mayo de 1975 y de 6 de marzo de 1987, y en España, a través de las leyes 11/1981 y 21/1987.

A continuación se analizará esta etapa en la que ingresa el Derecho chileno, con la Reforma del 2013, que es un estado previo al cuidado conjunto como derecho fundamental de los padres y de los hijos, que es el sistema generalmente aceptado en los ordenamientos jurídicos que actualmente se analizan.

\section{A. Italia antes de la Reforma del 2006}

Italia es un excelente ejemplo de un sistema jurídico que va mutando lentamente desde uno de asignación exclusiva a uno de los padres, a otro con un sistema con facultades y derechos con contrapesos, inspirados en los principios de la igualdad de los padres y del interés superior del niño. Pero además, el Derecho italiano tiene el mérito de haber sido el primero de los ordenamientos jurídicos en distinguir entre titularidad y ejercicio de la patria potestad, a través del Codice Civile de 1865. Este sistema, que distingue entre facultades exclusivas y conjuntas, se perfeccionaría mediante las leyes de 14 de mayo de 1975 y 6 de marzo de $1987^{7}$. La regla general consistía en que el ejercicio de la patria potestad correspondía al padre, que convive con los hijos, y la titularidad

\footnotetext{
${ }^{6}$ Sobre esta evolución ver: Barcia Lehmann, Rodrigo, "Facultades y derechos compartidos respecto de los hijos: una mirada desde el derecho comparado", en: Revista de Derecho (Coquimbo), en proceso de publicación, $42 \mathrm{p}$.

${ }^{7}$ De la Haza Díaz, P., “Notas sobre el ‘Affidamento’ Familiar en el Derecho Italiano y el Acogimiento Familiar en el Código Civil Español”, en Revista General de Legislación y Jurisprudencia, año CXXXVI, núm. 3 , Tomo XCV, Editorial Reus, Madrid, septiembre 1987, pp. 959-1007.
} 
era conjunta (exartículos 317-2 y 317 bis). En los casos de separación, divorcio y nulidad, que son los que nos interesan, el artículo $155.3^{\circ}$ del Codice establecía que la patria potestad correspondía al padre al que se confían los hijos; pero el padre no guardador no quedaba excluido de la guarda. Ello se debería a que las decisiones de importancia se mantenían como conjuntas. Este sistema establecía un régimen conjunto para las decisiones importantes, que era subsidiario, por cuanto el juez podía disponer otra cosa. Así, el sistema era de régimen ejercicio exclusivo, con exclusión de las decisiones relevantes, y siempre manteniéndose la posibilidad del padre excluido de recurrir a la instancia judicial. De esta manera, el exartículo $155.5^{\circ}$ establecía que “...salvo disposición diversa del juez, tiene el ejercicio exclusivo de la patria potestad...”, y agregaba “...las decisiones de mayor interés para los hijos son adoptadas por ambos cónyuges”. Sin perjuicio de ello, en esta etapa la jurisprudencia mantuvo el ejercicio conjunto, a pesar de la separación o divorcio - posibilidad que permitiría la norma precedente, pero solo a partir de la vigencia de la ley de 6 de marzo de $1987-^{8}$.

El sistema italiano, antes de la promulgación de la Ley 54/2006 de 8 de febrero, se adscribía al primer mecanismo de asignación de las facultades y derechos de filiación, o sea, exclusivo o unilateral a uno de los padres. A lo menos en consideración a lo que establecía el Codice. Así, en virtud de este Derecho, en los casos de divorcio de los padres, el tribunal debía determinar a cuál le correspondía la custodia -affidamento-. El tribunal decidía, de acuerdo con las aptitudes morales, la personalidad y la opinión de los padres y recurriendo a la determinación del interés moral y material de los hijos. También se aceptaba que los padres pudiesen celebrar acuerdos en esta materia; pero ellos estaban sujetos a la aprobación judicial. Posteriormente los tribunales impusieron a los padres el cuidado conjunto a petición de uno de ellos ${ }^{9}$. En los procesos de separación se consideraban los deseos de ambos padres y del menor, dependiendo de su madurez. También, el tribunal podía conceder de forma excepcional la custodia a un tercero. Sin perjuicio de lo cual, en el Derecho italiano, aunque un padre no tuviese la custodia, las decisiones importantes debían ser tomadas de forma conjunta. Asimismo, los tribunales, mientras se tramita el proceso de separación o nulidad, podían dictar órdenes temporales tendientes a implementar la participación de ambos padres en los destinos de sus hijos. La jurisprudencia italiana, después de la promulgación de la ley de divorcio de 6 de marzo de 1987, adoptó en muchos casos una especie de joint custody

\footnotetext{
${ }^{8}$ Incluso el sistema italiano consideraba para la situación de la separación de hecho el ejercicio conjunto, desde que a este respecto se aplicaba la regla general (art. 316), a pesar que habían fallos que resolvían a favor del padre o madre que convivía con el hijo. En cambio, respecto de la filiación no matrimonial, se prefería al padre que vivía con el hijo, salvo que el juez en el interés del hijo hubiese dispuesto otra cosa (art. 317 bis), otorgándose al otro progenitor una facultad-deber de vigilancia, instrucción, educación, etc.

${ }^{9}$ Así lo señala Del Vas González en los siguientes términos: "el artículo 6 de la ley del divorcio, después de la reforma de 1987, contemplaba la posibilidad de determinar la custodia conjunta y la custodia alterna como modalidades distintas de la custodia exclusiva, compartiendo la responsabilidad educativa común de los hijos pese a estar los cónyuges separados o divorciados".

Del Vas González, J. M., "Rottura della famiglia e interesse dei figli en el Derecho Civil italiano", en Revista Crítica de Derecho Inmobiliario, núm. 717, 2010, pp. 210-211.
} 
inspirada en el Derecho anglosajón. De esta forma, la referida Reforma, debido a toda la experiencia previa, estableció una especie de guarda alternativa, agregando al artículo que “...cuando el tribunal lo considere útil al interés del menor, atendiendo también a su edad, podrá disponer la custodia conjunta o alternativa" ${ }^{10}$.

\section{B. España antes de la Reforma del 2005}

En España, la Ley $\mathrm{N}^{\circ}$ 11/1981, de 13 de mayo, estableció la igualdad de ambos progenitores respecto de la titularidad y ejercicio de la patria potestad ${ }^{11-12}$. A las

${ }^{10}$ Roppo, V., Istituzione Di Diritto, Monduzzi Editore, 1996.

${ }^{11}$ Los alcances de la distinción entre titularidad y ejercicio de patria potestad se pueden apreciar de las palabras de García Cantero, que se queja por la no extensión de la distinción a los abuelos. De este modo, García Cantero señala que "puede acontecer que, por avatares de la vida, los abuelos de un menor hayan hecho de padres con él, pero jurídicamente nunca han llegado a ser titulares de la patria potestad sobre su nieto, ni siquiera por la vía oblicua de la adopción...", y destaca que de acuerdo con el art. 10 de la Comp. Aragón los abuelos pueden ejercer la autoridad familiar con los mismos derechos y obligaciones de los padres.

García Cantero, G., Las relaciones familiares entre nietos y abuelos según la ley de 21 de noviembre de 2003, Thomson Civitas, Cuadernos Civitas, Madrid, España, 2004, p. 19.

${ }^{12}$ Con relación al ejercicio y titularidad de la patria potestad ver: Albaladejo García, M., Comentarios al Código Civil y Compilaciones Forales, M. Albaladejo García, Editorial Revista de Derecho Privado, Editoriales de Derecho Reunidas, tomos VIII, vol. $2^{\circ}$ (artículos 618 a 656) y X, vol. X (artículos 774 a 805), editoriales Revista de Derecho Privado, 1986 y 1984; Barral Viñals, I., "La Potestad del Padre y de la Madre”, Capítulo 18, Derecho de Familia, en Maluquer de Motes (coord.), Carlos, Derecho de Familia, Bosch, Barcelona, 2000, pp. 370 a 394; Castán Vásquez, J.M., La Patria Potestad, editorial Revista de Derecho Privado, Madrid, 1960; Castán Vásquez, J.M, “La Llamada 'Patria Potestad de Hecho”, en Revista de Derecho Privado, julio-agosto de 1978, editorial Revista de Derecho Privado, Madrid, pp. 841 a 844; Castán Vásquez, J.M, "Comentario del artículo 156 del Código Civil”, en Comentarios al Código Civil y Compilaciones Forales, Edersa, Madrid, 1982, tomo IV; Castán Vásquez, J.M., "Comentarios a los artículos 154 a 170 del C.c.”, en Comentarios al Código Civil y Compilaciones Forales, Albaladejo García, M. Editorial Revista de Derecho Privado, Editoriales de Derecho Reunidas, tomo III, vol. $2^{\circ}$, editoriales Revista de Derecho Privado, 1982, pp. 55 a 259; Castán Vásquez, J.M, "El Problema de Ejercicio de la Patria Potestad por Padres Menores en el Derecho Argentino y en el Derecho Español”, en Revista de Derecho Privado, Editorial Revista de Derecho Privado, Madrid, 1982, pp. 816 a 821; Castán Vásquez, J.M, "La Patria Potestad sobre los Hijos Nacidos fuera de Matrimonio", en Revista de Derecho Privado, febrero de 1987, editorial Revista de Derecho Privado, Madrid, pp. 196 a 212; Castillo Martínez, C. C., La Privación de la Patria Potestad, editorial Práctica del Derecho, Valencia 2000; De la Cámara Álvarez, M., "El Nuevo Régimen Jurídico de la Filiación”, en La Reforma del Derecho de Familia, Matrimonio, Separación, Divorcio, Régimen Económico Matrimonial, Filiación y Patria Potestad, Jornadas Hispalenses sobre la Reforma del Derecho de Familia, Imprenta Sevilla S.A., 1982, pp. 239 a 323; De la Valgóma, M., "Notas sobre la Titularidad en el Ejercicio de la Patria Potestad", en Revista de la Facultad de Derecho de la Universidad Complutense, Primavera, 1981, núm. 62, Artes Gráficas Benzal, Madrid, pp. 90 a 104; De Prada González, J. M., "La Patria Potestad tras la Reforma del Código Civil”, en Anales de la Academia Matrisense del Notariado, Tomo XXV, Estudios sobre el Nuevo Derecho de Familia y Sucesiones, Editorial Revista de Derecho Privado, 1982; Díaz Alabart, S., "Comentarios a los Artículos 236-238", en Comentarios a la Reforma de Nacionalidad y Tutela, Tecnos, 1986, pp. 326 a 350; Díez-Picazo, L., "La Reforma del Código Civil en Materia de Patria Potestad", en La Reforma del Derecho de Familia, Matrimonio, Separación, Divorcio, Régimen Económico Matrimonial, Filiación y Patria Potestad, Jornadas Hispalenses sobre la Reforma del Derecho de Familia, Imprenta Sevilla S.A., 1982, pp. 291 a 323; Díez-Picazo, L., "Notas sobre la Reforma del Código Civil en Materia de Patria Potestad”, en Anuario de Derecho Civil, Tomo XXXV, Fascículo I, enero-marzo, 1982, Artes Gráficas y Ediciones, Madrid, pp. 3 a 20; Linacero De la Fuente, M. A., Régimen Patrimonial de la Patria Potestad, Editorial Montecorvo, S.A., Madrid, 1990, pp. 17 a 98; Linacero De la Fuente, M. A, "Custodia de 
facultades y los deberes derivados de la filiación se les suele denominar como patria potestad residual y muchos de ellos derivan de la titularidad de la patria potestad, que necesariamente es conjunta. En dicho ordenamiento jurídico, el padre no custodio tiene facultades y derechos conjuntos -que derivan de la titularidad de la patria potestad-, e incluso se afirma que el padre no custodio posee similares derechos al padre que tiene la guarda y custodia en cuanto al ejercicio de la patria potestad ${ }^{13}$. La mayoría de los autores que en España han tratado este tema, destacan el necesario equilibrio que debe existir entre las facultades y derechos que se desprenden de la patria potestad, sobre todo en los casos de separación o divorcio. En este sentido, Zarraluqui Navarro señala que "[1] as crisis matrimoniales y de pareja no alteran, salvo casos concretos y excepcionales, el contenido de la patria potestad, si bien por razones evidentes de falta de convivencia de los padres es necesario modificar el cumplimiento de algunas de sus facultades e incluso repartirlas". Agrega que, en los casos de separación, el juez deberá decidir sobre la custodia y el régimen de comunicación y establecimiento del padre no custodio, y finalmente señala que "[s]in embargo, el resto de derechos y obligaciones que integran la patria potestad (responsabilidad parental), tales como velar por los hijos, tomar las decisiones importantes que sean necesarias en su beneficio, así como representarlos y administrar sus bienes, serán ejercidas conjuntamente por ambos progenitores” ${ }^{4}$. Por

Menores. Conflicto entre el Padre y los Abuelos”, en Revista del Poder Judicial, núm. 30, junio, 1993, Publicaciones del Poder Judicial, pp. 145 a 158; López Pérez, M. del C., La Patria Potestad del Titular, Publicaciones de la Universidad de Valladolid, 1982; López Pérez, J., Prórroga y Rehabilitación de la Patria Potestad, Bosch Editorial, S.A., Barcelona, 1992, pp. 9 a 163; Magaz Sangro, C., "La Acomodación de los Acuerdos, Medidas o Efectos a Otras Circunstancias", en Revista Jurídica General, Boletín del Ilustre Colegio de Abogados de Madrid, núm. 8,

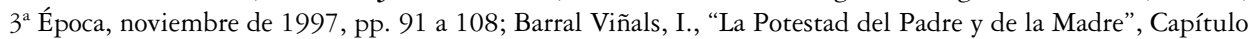
18, en Maluquer de Motes, Carlos (coord.), Derecho de Familia, Bosch, Barcelona, 2000, pp. 370 a 394; MartínGranizo Fernández, M., "La Patria Potestad Prorrogada y la Rehabilitación después de su Reforma por la Ley 13/1984, de 24 de octubre”, Revista de Legislación y Jurisprudencia, Año CXXXIV, junio, 1985, núm. 6, segunda época, Tomo XC (258 de la Colección), Editorial Reus, pp. 857 a 935; Pau Pedrón, A., "La Nueva Regulación Alemana sobre la Patria Potestad", en Anuario de Derecho Civil, Tomo XXXV, Fascículo III, julio-septiembre, Artes Gráficas y Ediciones, Madrid, 1982, pp. 723 a 749; Rivero Hernández, F., "Las Relaciones Paterno-Filiales (Título, Ejercicio y Contenido de la Patria Potestad, Guarda y Cuidados y Régimen de Visitas) como Contenido del Convenio Regulador", en Convenios Reguladores de las Crisis Matrimoniales, Instituto de Ciencias para la Familia, ediciones universidad de Navarra S.A., Pamplona, 1989, pp. 69 a 125; Rivero Hernández, F., en Álbacar López, J. L., "Comentarios del Código Civil “, tomo I, Centro de Publicaciones, Madrid, 1991; Romero Girón, J., "Patria Potestad", en Revista del Ilustre Colegio Notarial de Granada, Academia Granadina del Notariado, núm. 63, marzo 1986, Sección Tercera, pp. 495 a 559 y Sancho Rebullida, F. de A., "Título V. De la Patria Potestad y de la Filiación”, en Albaladejo García, M. Editorial Revista de Derecho Privado, Editoriales de Derecho Reunidas, Comentarios al Código Civil y Compilaciones Forales, Tomo XXXVI, vol. 1º, Leyes 42 a 81, Compilación del Fuero de Navarra, Editorial de Derecho Reunidas, Madrid, 1990.

13 Rivero Hernández, F., "La Guarda y Custodia de los Hijos y Derechos de Visita tras la Crisis Matrimonial”, en Cevilla Grarzón, M. D. (coord.), IV Seminario de Estudios Jurídicos y Criminológicos, Servicio de Publicaciones de la Universidad de Cádiz, 1996, p. 86.

${ }^{14}$ Zarraluqui Navarro, E., Guarda y custodia vs. patria potestad en cuanto a la residencia de los hijos menores, Derecho de Familia, Novedades en dos perspectivas, Asociación Española de Abogados de Familia, Dykinson, Madrid, España, 2010, pp. 161 y 162. 
otra parte, también existen deberes -facultades relacionadas con la guarda, que tiene el padre no custodio, como el deber de vigilancia y control-.

En el Derecho español la patria potestad era conjunta, de acuerdo con el exartículo 154 del CCE, que establecía que "los hijos no emancipados están bajo la potestad del padre y de la madre" ${ }^{15}$. La mayoría de los autores entendía, antes de la Reforma del 2005, que el artículo 154 del CCE se refería a la titularidad de la patria potestad, pero no a su ejercicio. Sin embargo, ello no quería decir que el ejercicio de la patria potestad no fuese conjunto, ya que el artículo $156.1^{\circ}$, del mismo cuerpo legal, establece que "la patria potestad se ejercerá conjuntamente por ambos progenitores o por uno solo con el consentimiento expreso o tácito del otro”. Así, en el Derecho español, como en el italiano y también en el argentino, la asignación de facultades y derechos de filiación se articula sobre la dicotomía de titularidad y ejercicio de la patria potestad.

Así las cosas, en España, antes de la Reforma del 2005, el criterio diferenciador entre los derechos del padre y la madre era en cierta medida similar al chileno, antes de la Reforma del 2013, al distinguir según si los padres vivían o no juntos; pero las consecuencias de ello eran diferentes. En el Derecho español, para asignar la patria potestad, se hace la siguiente distinción:

a) Si los padres viven juntos: el ejercicio de la patria potestad es conjunto.

b) Si los padres viven separados el juez decide de acuerdo con los artículos $159 \mathrm{y}$ $156.6^{\circ}$ del $C C E^{16}$.

El supuesto de la letra (a) era compartido, a lo menos en parte, por el Derecho chileno y español ${ }^{17}$; pero ahí se acababan las semejanzas, desde que el criterio de asignación legal supletorio era diferente. La diferencia más relevante era que, en el Derecho español, la diferenciación entre los derechos y facultades de los progenitores se adecuan de acuerdo con los principios de interés superior del niño y la igualdad de los padres. En cambio en nuestro Derecho se optaba por aplicar como asignación legal supletoria la regla de la preferencia materna. La Reforma del 2013 seguiría de cerca al Derecho español en este aspecto, al establecer en el nuevo artículo $225.3^{\circ}$ que [a] falta del acuerdo del inciso primero (se refiere a un eventual acuerdo de custodia compartida), los hijos continuarán

${ }^{15}$ La Ley $\mathrm{N}^{\mathrm{o}}$ 13/2005, de 1 de julio, que permitió el matrimonio entre personas del mismo sexo, modificó la referencia al padre y la madre, por padres.

${ }^{16}$ Los artículos 159 y $156.5^{\circ}$ del CCE son fundamentales para determinar la asignación de la patria potestad, ninguna de las dos normas fue modificada por la ley del 2005. El artículo 159 del CCE establece que "[s]i los padres viven separados y no decidieren de común acuerdo, el juez decidirá, siempre en beneficio de los hijos, al cuidado de qué progenitor quedarán los hijos menores de edad. El juez oirá, antes de tomar esta medida, a los hijos que tuvieran suficiente juicio y, en todo caso, a los que fueren mayores de doce años". La otra norma, que se refiere a esta materia, es el artículo $156.5^{\circ}$ del CCE, que dispone que si los padres viven separados la patria potestad se ejercerá por aquel con quien el hijo conviva. El conflicto entre estas normas ha provocado más de un dolor de cabezas a la doctrina española, que no es del caso tratar.

${ }^{17}$ Así lo establecía el exartículo $224.1^{\circ}$ y lo consigna el actual artículo 224 del CCCh, respecto del cuidado personal; pero respecto de la patria potestad, a falta de acuerdo, ella corresponde al padre (exartículo 
bajo el cuidado personal del padre o madre con quien estén conviviendo" (lo destacado entre paréntesis es mío).

En resumen, el Derecho español articula un sistema de facultades y derechos paternos, que en los casos de separación de los padres, depende de los conceptos de patria potestad -que comprende tanto su titularidad como su ejercicio conjunto-y el cuidado o guarda personal exclusivo ${ }^{18}$.

Las facultades y derechos del padre no custodio se pueden sintetizar de la siguiente forma: derecho a reunión con el hijo en el lugar que habite (artículos 9.3, $35.1^{\circ}$ y 35 de la Convención de la Haya de 1996), derecho de relación y comunicación (artículos 90.3ㅜ, 91 y 94 del $C C E$ ), derecho a velar por los hijos (artículo $154.1^{\circ}$ del $C C E^{19}$ ), derecho de vigilancia y control (artículos 92.2 $, 158,103.1^{\circ}, \mathrm{N}^{\circ} 1$, párrafo 1 y 170 del $\left.C C E\right)^{20}$ y derecho de información respecto de la situación del niño (artículo $158.2^{\circ}$ del CCE). Estas facultades se traducen fundamentalmente en un derecho negativo del padre no custodio a oponerse a las acciones que considere perjudiciales para su hijo (artículos $156.2^{\circ}, 158.1^{\circ}$,

224. $2^{\circ}$ del CCCh). A su vez, el artículo 154 del CCE, en su redacción actual, dispone que "[1]os hijos no emancipados están bajo la potestad de los padres.

La patria potestad se ejercerá siempre en beneficio de los hijos, de acuerdo con su personalidad, y con respeto a su integridad física y psicológica.

Esta potestad comprende los siguientes deberes y facultades:

$1^{\circ}$ Velar por ellos, tenerlos en su compañía, alimentarlos, educarlos y procurarles una formación integral.

$2^{\circ}$ Representarlos y administrar sus bienes.

Si los hijos tuvieren suficiente juicio deberán ser oídos siempre antes de adoptar decisiones que les afecten.

Los padres podrán, en el ejercicio de su potestad, recabar el auxilio de la autoridad.

Este artículo fue modificado por las Leyes $13 / 2005$ y 54/2007. Antes de esta reforma se establecía que "[1]os hijos no emancipados están bajo la potestad de sus progenitores.

La patria potestad se ejercerá siempre en beneficio de los hijos, de acuerdo con su personalidad, y comprende los siguientes deberes y facultades:

$1^{\circ}$ Velar por ellos, tenerlos en su compañía, alimentarlos, educarlos y procurarles una formación integral.

$2^{\circ}$ Representarlos y administrar sus bienes.

Si los hijos tuvieren suficiente juicio deberán ser oídos siempre antes de adoptar decisiones que les afecten.

Los padres podrán en el ejercicio de su potestad recabar el auxilio de la autoridad. Podrán también corregir razonable y moderadamente a los hijos".

Sin perjuicio de lo cual, para tratar las facultades y deberes de filiación en el Derecho español se debe distinguir entre titularidad y ejercicio de la patria potestad.

${ }^{18} \mathrm{La}$ diferenciación entre estas tres figuras es esencial, pero ello excede con creces este estudio. Al respecto M. García Pastor define la guarda o custodia como «el conjunto de funciones parentales que requieren el contacto constante entre el adulto y el niño». Sin embargo, para Lathrop esta concepción de guarda y custodia es más bien restringida, por cuanto se contrapone con una más amplia que alcanza a la educación y formación integral de los hijos, y que sobrepasa el mero cuidado o protección física de estos. La concepción de Lathrop discrimina funcionalmente a los padres, salvo que se entienda que el cuidado es en parte conjunto.

Lathrop Gómez, F., Custodia compartida de los hijos, La Ley, Madrid, España, 2008, p. 58.

${ }^{19}$ El referido artículo es del siguiente tenor:

"Artículo $154.3^{\circ}$ Esta potestad (se refiere al ejercicio de la patria potestad) comprende los siguientes deberes y facultades: $1^{\circ}$ Velar por ellos, tenerlos en su compañía, alimentarlos, educarlos y procurarles una formación integral" (lo destacado entre paréntesis y cursiva es mío).

${ }^{20}$ Un antecedente de esta facultad -deber se puede encontrar en el artículo $20.2^{\circ}$ de la Ley de Divorcio de 1932. 
$\mathrm{N}^{\mathrm{3}} 3$ y 166 del $C C E$ ). Pero el padre no custodio, además de estas facultades, participa en la educación, entretenimiento, elección de la religión del menor, etc., y todos los aspectos que se desprenden de la titularidad y ejercicio conjunto de la patria potestad (aspecto positivo de la titularidad y ejercicio de la patria potestad) ${ }^{21}$.

\section{Francia antes de la Reforma de 1993}

En Francia, la ley de 4 de junio de 1970 estableció un sistema de autoridad parental unilateral a favor de la madre, para los hijos no matrimoniales (exart. 374 del Code), y de guarda exclusiva para uno de los padres para los hijos matrimoniales (exart. 373-2 del Code). En el caso de los hijos matrimoniales el padre no guardador tenía a su favor un régimen de visitas y vigilancia (art. 372-2 del Code). Lentamente, vía jurisprudencia, se comenzaron a otorgar estos derechos al padre no custodio respecto de los hijos no matrimoniales. Este proceso, hacia una igualación de los derechos de los padres, se aceleraría con la promulgación de las leyes de 22 de julio de 1987 y 8 de enero de 1993. La Reforma de 1987 fue de suma importancia por cuanto estableció un ejercicio conjunto de la autoridad parental, que recogía la guarda conjunta que ya había sido reconocida por la jurisprudencia de la Corte de Casación (D. 1984, J.53 y JCP. 1984. II.20163 $)^{22}$. En dicha Reforma se modificaría el artículo 374 del Code, estableciendo el

${ }^{21}$ Sin perjuicio de lo aquí señalado, la asignación de las facultades y derechos de filiación, en el Derecho español, en la actualidad es conjunta, como se desprende de los fallos del TS de 7 de julio del 2011, Rol N 496 del 2011 ( $\mathrm{N}^{\circ}$ recurso: 1221/2010) y 22 de julio del 2011, Rol No 579 del 2011 ( $\mathrm{N}^{\circ}$ recurso: 813/2009).

El primer fallo de la referencia, que tiene como ponente a Encarnación Roca Trías, resuelve en su parte considerativa que: "[1]a sección N $\mathrm{N}^{\circ} 6$ de la Audiencia Provincial de Alicante dictó nueva sentencia el 22 marzo 2010, en la que se desestimó el recurso presentado por D. Pedro Jesús contra la sentencia del Juzgado de $1^{\text {a }}$ Instancia, partiendo de los siguientes argumentos: a) «La figura de la custodia compartida es de interpretación restrictiva y de aplicación excepcional», es decir, el TS desecha el argumento del tribunal «a quo» que señala que la custodia compartida es excepcional y estima que su aplicación dependerá del interés superior del niño”. Así, la misma sentencia falla que “...los hijos menores de ambas partes, Daniela, Carlos y Doroteo, sometidos a la patria potestad de ambos progenitores quedan bajo la guardia y custodia compartida de ambos progenitores, alternándose los tiempos de estancia con cada progenitor por periodos semanales, produciéndose la entrega de uno al otro los domingos a las 20 horas. Hasta que el menor, Doroteo, cumpla las tres años, el progenitor con el que los menores no se encuentren esa semana, podrán visitarlos a diario entre semana, durante una hora. / 2.- A partir de que el menor, Doroteo, cumpla un año, las vacaciones escolares de los menores se repartirán por mitad entre ambos progenitores".

22 Como destaca García Pastor, respecto de la Reforma francesa de 1987, "[1]o cierto es que, quizás por el mero efecto pedagógico, o quizás porque la ley de 22 de julio de 1987 supo recoger las verdaderas tendencias de la evolución de la sociedad francesa, desde que se promulgó dicha ley el sistema de ejercicio conjunto se ha convertido en la norma en la práctica judicial (establecido en más del 60\% de las sentencias de separación y divorcio (hay nota al pie), con al parecer excelentes resultados. Los jueces no se han limitado a establecer el ejercicio cuando ambos progenitores lo piden, sino también en muchos casos de desacuerdo, reservando el ejercicio unilateral para casos extremos en los que, por la gravedad del conflicto existente entre los padres, por la personalidad de uno de ellos o por el abandono efectivo de los niños por uno de los progenitores, el ejercicio conjunto resulta inviable”.

García Pastor, M., La situación jurídica de los hijos cuyos padres no conviven: Aspectos personales, Monografías, Madrid, España, McGraw-Hill, 1997, p. 167. 
ejercicio conjunto respecto de la autoridad parental, independientemente de la convivencia de los padres. La ley de 8 de enero de 1993 establecería el sistema actual por el que la regla general es la autoridad conjunta, reservándose el ejercicio indistinto para los casos en que el juez lo decrete de forma excepcional conforme al interés superior ${ }^{23}$.

Por otra parte, el exartículo 288 del Code, antes de su supresión por la Ley $\mathrm{N}^{0} 305$, de 4 de marzo del 2002, relative à l'autoritéparentale ${ }^{24}$, consagraba este deber-facultad en los siguientes términos: "[e]l esposo al que la guarda de los hijos no le ha sido confiada, conserva el derecho de vigilar su desarrollo y educación, debiendo contribuir en proporción a sus recursos". En igual sentido, según el artículo 356.1 del CP francés, es obligación del padre, que ostenta el ejercicio de la patria potestad, comunicar las decisiones que tome en torno al menor y especialmente su cambio de domicilio; agregando el artículo 373-2-1, que "[e]ste padre (se refiere el no custodio) conservará el derecho y el deber de cuidar del sustento y educación del hijo. Habrá de ser informado sobre las decisiones importantes relativas a la vida de este último. Y deberá respetar la obligación que le impone el artículo 371-2" (lo destacado entre paréntesis y cursiva es mío).

El deber de vigilancia no fue definido por el Code, pero comprendía el control sobre el ejercicio del derecho de guarda en interés del hijo, otorgar información sobre su salud, educación, y actividades recreativas y atingentes a su vida personal ${ }^{25}$.

D. Alemania antes de los fallos del TEDH, de fecha 3 de diciembre del 2009, y del TC alemán de 21 de julio del 2010

El sistema alemán podía calificarse, hasta hace muy poco tiempo, como un sistema intermedio por cuanto estaba transitando hacia un sistema de equilibrio de facultades y derechos entre los padres. La situación era un tanto extraña desde que se mantenía un sistema de asignación exclusiva con resguardos para el padre que no tiene la patria potestad (elterliche sorge); pero se distinguía entre hijos matrimoniales y no matrimoniales. Sin perjuicio de lo que la sentencia del TC alemán, de fecha 21 de septiembre del $2010^{26}$, vendría a modificar en parte este panorama. Las reglas que se establecían, en dicho país, antes del referido fallo, eran las siguientes:

${ }^{23}$ La ley de 23 de diciembre de 1985 establecería un régimen más igualitario para la administración de los bienes del hijo.

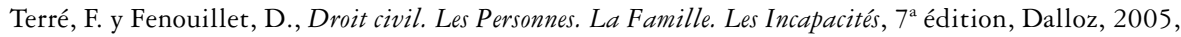
pp. 962 a 968 .

${ }^{24}$ Ver:http://legifrance.org/affichTexte.do;jsessionid=E4C4C3BBB8415D422759BE137FEF408C. tpdjo09v_3 cidTexte $=$ JORFTEXT000000776352\&idArticle $=\&$ dateTexte $=20121219$ [ sitio visitado el 13 de diciembre del 2012].

${ }^{25}$ Se puede consultar jurisprudencia a partir del fallo del Tribunal de Gran Instancia de París de 23 de febrero de 1971.

${ }^{26}$ Esta sentencia estableció importantes derechos y facultades para los padres no matrimoniales, y ella se pronuncia aplicando el fallo del TEDH, de fecha 3 de diciembre del 2009, por el cual en los autos 
a) En caso que los padres estaban casados la patria potestad era conjunta.

b) En caso que los padres no estuviesen casados y viviesen juntos, la patria potestad correspondía a ambos padres en la medida que ella fuese establecida a través de una declaración, o contraigan matrimonio. En los casos en que los padres no viviesen juntos podrían ejercerla conjuntamente, pero de común acuerdo ( $\$ 1626 \mathrm{a}$, $\mathrm{N}^{\circ} 1$ del $\left.B G B\right)$; en los demás casos la ejercería la madre ( $\$ 1626 \mathrm{a}, \mathrm{N}^{\circ} 2$ del $\left.B G B\right)$.

De este modo, el Código Civil alemán realiza las siguientes diferencias:

i) Si los padres viven separados y ejercen la patria potestad de forma conjunta puede solicitar cada uno de ellos la patria potestad exclusiva ( $\$ 1671$ del BGB). Se otorgará la patria potestad exclusiva o en parte a través del Tribunal de Familia, considerando los siguientes requisitos:

(i) El otro padre o madre (según sea el caso) consiente en la patria potestad, salvo que el niño tenga catorce años y se niegue al traspaso.

(ii) Se extingue la patria potestad conjunta y se traspasa la patria potestad al peticionario según el bienestar del niño.

En el caso de que los padres vivan separados y a la madre le corresponda la patria potestad, de acuerdo con $\S 1626$ a del $B G B$, puede el padre solicitar la patria potestad con el consentimiento de la madre, en la medida que ello corresponda al bienestar del niño ( $\$ 1672$ del $B G B)$.

ii) Si los padres viven separados, pero mantienen la patria potestad conjunta.

El $\S 1687$ del $B G B$ establece que para el ejercicio de la patria potestad conjunta, en el caso que los padres vivan separados, debe distinguirse entre los asuntos importantes y los asuntos cotidianos o de menor importancia. Los primeros serán decididos por ambos padres; los segundos serán decididos por el padre que conviva con el menor. Pero ambas situaciones pueden modificarse por el tribunal cuando el interés del niño así lo determine ( $\$ 1687$ Abs. 2 del $B G B)$.

Sin perjuicio de lo anterior, y a pesar que la patria potestad se radique en la madre, al padre privado del ejercicio de la patria potestad le asiste una serie de facultades y derechos, como los de información con relación a la situación personal del niño; a mantener contacto y comunicación con los mismos. A su vez, en los supuestos de ruptura, en caso que la responsabilidad parental continúe siendo conjunta, se requerirá el acuerdo de ambos progenitores para adoptar decisiones sobre asuntos de relevancia para la vida del menor; pero naturalmente los aspectos cotidianos de la vida del niño son de cargo del padre que tiene el cuidado personal.

\footnotetext{
“Zaunegger v. Germany" ( ${ }^{\circ}$ 22028/04) se condenó al Estado alemán por discriminar entre los hijos matrimoniales y no matrimoniales.

Ver: http://www.bverfg.de/entscheidungen/rs20100721_1bvr042009en.html y http://www.bverfg.de/ entscheidungen/rs20100721_1bvr042009.html [sitio visitado el 13 de diciembre del 2012].
} 


\section{E. El Reino Unido antes de la Reforma de la ley de la «Children Act» de 1989}

En el siglo XIX el concepto de guarda comenzó a hacerse difuso, señalándose doce conceptos diferentes de guarda; y el concepto de custodia pasó a ser de dos clases (amplio y restringido). En sentido amplio, la custodia comprendía todos los derechos que los padres tienen sobre sus hijos. Y la custodia, en sentido restringido, alcanzaba solo al poder físico que se tiene sobre el niño. Además, la custodia no será ejercida por uno de los padres de forma exclusiva ${ }^{27}$. La Ley de Matrimonio de 1973 (Matrimonial Causes Act) cambió el escenario precedente, al regular los derechos y facultades del padre no custodio. Hasta los años setenta se entendió que la custodia solo comprendía la tenencia del menor (right to possesion). En el Reino Unido, la sentencia de divorcio otorgaba la custodia a uno de los padres y el cuidado y control del menor al otro ${ }^{28}$. Pero posteriormente se entendió a la custodia como un conjunto de derechos y facultades (bundles of rights and powers), que incluía su educación, religión, consentimiento para operaciones médicas, etcétera. Entonces, un padre podía tener al hijo bajo su cuidado y, el otro, tomar decisiones en otras materias, como su educación. Sin embargo, las Cortes fueron renuentes a entender que la custodia concedía más derechos que aquellos específicamente establecidos en la sentencia. H K Bevan señala que, en el Reino Unido, se distinguía entre guardianship y custody. Esta distinción, como se aprecia en el caso Hewer v. Bryant, se hace tanto en un sentido amplio como en uno restringido ${ }^{29}$. Sin perjuicio de ello, en dicha causa, el juez Sachs consideró como equivalentes custody y guardianship. En cambio, en otros casos la guardianship se limitaba a los bienes o la persona del menor, y no a ambos aspectos, como se entiende si ambas expresiones se hacen sinónimos. En una última acepción el término custody comprendía a la patria potestad o parens patriae.

En definitiva, el problema se radicaba en que mientras la ley distinguía entre estos dos términos, la Corte solía hacerlos equivalentes ${ }^{30-31}$.

Posteriormente, dichos conceptos variarían y se entendería que la custodia era el conjunto de derechos de los padres que provenían del reconocimiento del hijo. Este concepto se mantendría hasta ahora. En cambio, la guarda consistía en "un deber de resguardar respecto del menor". La Children Act de 1975 modificaría este escenario, estableciendo tres conceptos que vendrían a sobrepasar los antiguos conceptos de guarda y custodia. Estos tres conceptos son los deberes y derechos paternos y la custodia real y legal. Y, finalmente, la Reforma de 1989, implementada por la Children Act, dejaría de

${ }^{27}$ Cretney, S. M., Principles of Family Law, London Sweet \& Maxwell, Londres, 1984, pp. 296-299.

${ }^{28}$ De acuerdo con S. M. Cretney, existía en los años ochenta una tendencia a otorgar el cuidado y control de los hijos muy pequeños a la madre, pero la custodia al padre, ya que en el largo plazo él tomaba las decisiones que afectan a la educación del menor.

Cretney, S. M., Principles of Family Law, London Sweet \& Maxwell, Londres, 1984, p. 401.

${ }^{29}$ Bevan, H. K., Child Law, Butterworths, London, 1989, p. 36.

${ }^{30}$ Ibidem. p. 37.

${ }^{31}$ En igual sentido, S. M. Cretney señalaba que, de acuerdo con el Derecho común, se debía distinguir entre custodia y guarda. La custodia comprendía el conjunto de derechos sobre el menor y la guarda era la atribución de dichos derechos a un individuo o individuos. 
lado los conceptos anteriores para adscribirse a través de la parental responsibility como un mecanismo de equilibrio entre las facultades de los padres, más que un mecanismo de asignación de facultades y derechos que considera la situación del padre no custodio (adscribiendo este sistema a los sistemas con contrapesos de facultades y derechos entre los padres).

\section{F. Breve recapitulación en torno a la situación del Derecho comparado}

El trabajo precedente analiza varios ordenamientos jurídicos europeos que optaron, durante los años setenta hasta entrado principios de este siglo, por un sistema de asignación exclusiva de facultades y derechos de filiación. En todos ellos -independientemente de que han mutado a sistemas de facultades y derechos conjuntos- ha existido una especial preocupación por el establecimiento de facultades y derechos respecto del padre no custodio.

La forma de articular estos sistemas podría sintetizarse de la siguiente forma:

a) Un sistema de titularidad conjunta, pero de ejercicio separado o indistintamente para cada uno de los padres. En la práctica este sistema se aplica de dos formas: (i) Restringidamente solo a determinados actos, como en Austria (en que solo se aplicaba a los actos de representación). (ii) Ampliamente a todo tipo de actos, tanto patrimoniales como personales.

b) Un sistema de actuación conjunta de los padres, tanto en lo que respecta a la titularidad como al ejercicio de la patria potestad. Sin embargo, dentro de este supuesto se admite el ejercicio unilateral de la patria potestad en algunos supuestos excepcionales regulados por la ley. El sistema adoptado por el Código Civil español es de actuación conjunta, tanto en la titularidad como en el ejercicio. En España se acepta el cuidado o custodia exclusivo con facultades y derechos para el padre no custodio, pero de forma excepcional por cuanto el sistema ha derivado jurisprudencialmente a un sistema de patria potestad y custodia compartidos.

c) Ejercicio indistinto de la patria potestad, como regla general y conjunto para los actos importantes.

Finalmente, el sistema precedentemente descrito sería remplazado, en la mayoría de los países precedentemente indicados, por un sistema de contrapeso de facultades y derechos que, en la práctica, se asemeja mucho a un sistema de patria potestad, cuidado, responsabilidad o autoridad conjunto. Nosotros, como se verá, hemos vivido de espalda a estos procesos, por cuanto hasta la reciente Reforma de la Ley 2013 teníamos un sistema de asignación de cuidado personal legal y judicial arbitrariamente concedido a la madre. Y lo que es peor, nuestro sistema no articulaba un sistema de facultades y derechos para el padre no custodio. De esta forma, los padres separados no tenían las facultades y derechos que se establecían en la mayoría de los ordenamientos jurídicos, violándose los derechos de los padres y de los hijos, que tenían naturalmente padres ausentes. Naturalmente la Reforma del 2013 es un avance, pero la interpretación que 
se hace de sus reglas debe acercarnos a la situación actual del Derecho comparado, más que encerrarnos en las Reformas analizadas que corresponden a un estadio ya abandonado en el Derecho comparado.

\section{El SISTEMA CHILENO DE ASIGNACIÓN DEL CUIDADO PERSONAL Y AUTORIDAD PARENTAL Y DE FACULTADES Y DERECHOS DEL PADRE NO CUSTODIO ANTES DE LA REFORMA DEL 2013}

En realidad haciendo un gran esfuerzo y dejando aparte las categorías conceptuales que establece el Derecho chileno -que son relevantes como la autoridad parental, el cuidado personal y la patria potestad-, el presente trabajo se centrará en la forma de distribución de las facultades y derechos de los padres, en caso de estar ambos separados. La diferencia fundamental consiste en el hecho de que los padres vivan o no juntos.

La categorización en Chile de la autoridad parental ha sido tradicionalmente exigua y se ha convertido en una categoría accesoria al cuidado personal. Así, en la discusión del Proyecto de Ley de Filiación se señaló que la autoridad parental debía recaer en el padre que ostenta el cuidado personal ${ }^{32}$. No se analizará entonces dicha figura, que es en todo caso esencial, por cuanto si se entiende que la autoridad parental es conjunta, se podría cumplir con el rol que se le ha asignado al Derecho de la infancia, como un Derecho que protege y desarrolla, de mejor forma, las facultades y derechos de los padres con relación a sus hijos ${ }^{33}$. En el Proyecto de Reforma del 2013 no se hace referencia a la autoridad parental, pero sí se trató la relación de esta figura con la corresponsabilidad que se estableció en el referido Proyecto de Ley ${ }^{34}$.

\section{A. Sistema chileno de asignación del cuidado personal antes de la Reforma del 2013}

El Derecho chileno, en caso de que los padres estuviesen separados, establecía una forma de asignación legal supletoria, conforme a la cual se aplicaba lo que se denominó la regla denominada de la "preferencia materna". Esta regla era una verdadera reliquia del Derecho y fue conocida en los países anglosajones como tender years doctrine. En el caso chileno tenía la particularidad de extenderse a toda la vida del menor. Así, a pesar de que esta regla solo se aplicaba en los primeros años de lactancia, en Chile tenía un ámbito de aplicación temporal casi absoluto. En este sentido, el exartículo $225.1^{\circ}$ del

${ }^{32}$ Historia de la Ley. Compilación de la Biblioteca del Congreso Nacional, Santiago, año 2000, Volumen II, p. 2741.

${ }^{33}$ Barcia Lehmann, R, Fundamentos del Derecho de Familia e Infancia, Editorial Thomson, 2011, Santiago de Chile, pp. 468 a 504.

${ }^{34}$ Ver: "Historia de la Ley No 20.680. Introduce modificaciones al Código Civil y a otros cuerpos legales, con el objeto de proteger la integridad del menor en caso de que sus padres vivan separados”, en Biblioteca del Congreso (http://www.leychile.cl/Consulta/portada_hl?tipo_norma=XX1\&nro_ley=20680\&anio=2013), p. 295. 
CCCh establecía que [s] i los padres viven separados, a la madre toca el cuidado personal de los hijos $^{35}$. A su vez, la regla de asignación judicial estaba contemplada en el exartículo $225.3^{\circ}$ del $C C C h$, según el cual el cuidado personal del niño, que corresponde a la madre, solo podrá ser modificado mediante resolución judicial, cuando el interés del bijo lo haga indispensable, sea por maltrato, descuido u otra causa calificada.

Esta regulación dejaba supeditada la intervención judicial a una calificación del interés superior como un interés que opera solo en circunstancias calificadas. Además, la norma presentaba claros problemas de constitucionalidad que la doctrina civil venía acusando infructuosamente durante bastante tiempo ${ }^{36}$. Estos problemas habían sido aminorados parcialmente por la jurisprudencia de los tribunales, que se había desarrollado según las reglas y principios propios del Derecho de la infancia. En una primera etapa se estableció que el exinciso $2^{\circ}$ del artículo 225 del CCCh debía aplicarse según el exartículo 226 del mismo cuerpo legal. Esta norma establecía que [ $p$ ]odrá el juez, en el caso de inhabilidad física o moral de ambos padres, confiar el cuidado personal de los hijos a otra persona o personas competentes. Y como las inhabilidades físicas y morales era numerus clausus, por cuanto estaban establecidas en el artículo 42 de la LPM, las facultades del juez se reducían de forma dramática ${ }^{37}$.

${ }^{35}$ El Código Civil, al tiempo de su promulgación, establecía en el artículo 223 que a la madre divorciada (en realidad se refería a la madre separada), haya dado o no motivo al divorcio, toca el cuidar personalmente de los hijos menores de cinco años, sin distinción de sexo, y de las hijas de toda edad. Y agregaba que, sin embargo, no se le confiará el cuidado de los hijos, cuando por su depravación sea de temer que se perviertan, lo que se presumirá, si ha sido el adulterio de la madre lo que ha dado lugar al divorcio.

A su vez, las normas que regulaban el cuidado de los hijos han sufrido modificaciones en varias ocasiones desde la promulgación del CCCh. De este modo, bajo la vigencia del CCCh, el cuidado de los hijos correspondía a la madre, excepto en lo que respecta a los hijos varones mayores de cinco años que pasaban a estar al cuidado del padre. Para el legislador de la época el fundamento de estas distinciones estaba en que los hijos en su temprana edad requieren del cuidado de la madre. Sin embargo, los hijos varones debían seguir el ejemplo paterno. Las Leyes $\mathrm{N}^{\circ} 5.680 / 35$ y $\mathrm{N}^{\circ} 10.271 / 52$ siguieron el mismo criterio, pero aumentaron la edad del hijo varón para estar al cuidado paterno, la primera a diez años y la segunda a catorce años. Finalmente, la Ley $\mathrm{N}^{\circ} 18.802$ estableció que le correspondía a la madre el cuidado de todos los menores, cualquiera que fuese su sexo, salvo depravación de la madre. Estas reglas fueron modificadas levemente, sin un mayor debate, por la $L F$, que estableció la actual regulación. La modificación consistió en que no se exigió depravación de la madre para que el cuidado lo tuviese el padre, sino se hizo una extraña mezcla entre causales de inhabilidad moral e interés superior del niño.

${ }^{36}$ Gómez de la Torre, Maricruz, "El nuevo derecho de la niñez", en: Estudios de Derecho Privado, Libro Homenaje al profesor Gonzalo Figueroa Yáñez, Editorial Jurídica de Chile, Santiago de Chile, 2008, p. 447; y Lathrop Gómez, Fabiola, “(In)constitucionalidad de la regla de atribución preferente materna del cuidado personal de los hijos del artículo 225 del Código Civil chileno”, en: Revista Ius et Praxis, Año 16, N² 2010, pp. 147 a 184.

${ }^{37}$ La norma reseñada es del siguiente tenor:

“Art. 42. Para los efectos del artículo 226 del Código Civil, se entenderá que uno o ambos padres se encuentran en el caso de inhabilidad física o moral:

$1^{\circ}$ Cuando estuvieren incapacitados mentalmente;

$2^{\circ}$ Cuando padecieren de alcoholismo crónico;

3. Cuando no velaren por la crianza, cuidado personal o educación del hijo;

$4^{\circ}$ Cuando consintieren en que el hijo se entregue en la vía o en los lugares públicos a la vagancia o a la mendicidad, ya sea en forma franca o a pretexto de profesión u oficio; 
La situación precedente afortunadamente fue corregida a partir de dos fallos de la Corte Suprema, de 24 de junio del 2010 y 16 de agosto del 2010, respectivamente, que fueron muy críticos con la labor desarrollada por las Cortes de Apelaciones a este respecto $^{38}$. En consideración a estos fallos se resolvió que otra causa calificada no se refería a los criterios establecidos en el artículo 42 de la LPM y que dichas causas debían valorarse según el interés superior del niño.

\section{B. Facultades y derechos del padre no custodio antes de la Reforma del 2013}

A pesar de que solo cabe calificar la interpretación precedente señalada por la Corte Suprema como correcta, los fallos del alto tribunal solo han asignado el cuidado personal al padre en casos en que la madre de alguna forma daña al hijo, es decir, solo han aplicado el principio del interés superior del niño en su vertiente de máxima protectora de la infancia ${ }^{39}$. De este modo, hasta antes de la Reforma del 2013, los tribunales no han asignado el cuidado personal considerando las habilidades parentales, sino a base de criterios que evidencian un cuidado precario de la madre respecto de su hijo. Pero, además, tampoco se han fijado facultades y derechos conjuntos o propios del padre no custodio, salvo el deber-facultad del padre no custodio de mantener un régimen de relación directo y regular que contemplaba la propia ley. Si se comparan las facultades y derechos que el ordenamiento jurídico chileno otorgaba al padre no custodio, solo cabía calificar al régimen de comunicación directo y regular como visitas.

Lamentablemente los autores que han sostenido la existencia de facultades y derechos para el padre no custodio no han tenido mayor acogida en la jurisprudencia de los tribunales. Así, se pueden consultar dos doctrinas que se han ocupado de este problema. Por una parte algunas autoras como Gómez de la Torrre y Lathrop señalan que existen facultades y derechos conjuntos con relación a los hijos. La primera es de la opinión que existen facultades y deberes conjuntos de los padres. Así, de acuerdo con el exartículo

$5^{\circ}$ Cuando hubieren sido condenados por secuestro o abandono de menores;

$6^{\circ}$ Cuando maltrataren o dieren malos ejemplos al menor o cuando la permanencia de este en el hogar constituyere un peligro para su moralidad;

$7^{\circ}$ Cuando cualesquiera otras causas coloquen al menor en peligro moral o material".

${ }^{38}$ Ellos corresponden a los autos Roles $N^{\circ} 608-2010$ y No $4.372-2010$.

39 Como no es posible ahondar en las consideraciones de la Corte Suprema, le sugiero al lector los siguientes tres artículos, que lo pondrán al día sobre este tema: Barrientos Zamorano, M., “¿Es interés superior o inferior del niño? Aplicación jurisprudencial del artículo 42 de la Ley de Menores a la luz del Código Civil”, en Estudios de Derecho Civil VII (X Jornadas de Derecho Civil), Viña del Mar, Elorriaga de Bonis, Fabián (coordinador), AbeledoPerrot, Legal Publishing Chile y Thomson Reuters, Santiago de Chile, 2012, pp. 117 a 126; Lathrop Gómez, F., "(In)constitucionalidad de la regla de atribución preferente materna del cuidado personal de los hijos del artículo 225 del Código Civil chileno”, en Revista Ius et Praxis, Año 16, núm. 2, 2010, p. 151 y Barcia Lehmann, R, "Una Mirada al Cuidado Personal, y en especial a los artículos 224, 225. $1^{\circ}$ y $3^{\circ}$ del Código Civil y 42 de la Ley de Protección de Menores, desde la perspectiva del interés superior del niño", en Estudios de Derecho Civil VII (X Jornadas de Derecho Civil), Viña del Mar, Elorriaga de Bonis, Fabián (coordinador), AbeledoPerrot, Legal Publishing Chile y Thomson Reuters, Santiago de Chile, 2012, pp. 127 a 145. 
236 del $C C C h$, los padres tienen conjuntamente el derecho y deber de educación con relación a sus hijos. En igual sentido Lathrop señalaba que "[a]sí, la custodia conjunta presupone más bien un concepto amplio de guarda y custodia, esto es, el ejercicio de la responsabilidad general del niño, en el entendido que comprende no solo el cuidado directo del hijo, sino el conjunto de derechos y deberes que se generan de la relación paterno-filial ( hay nota al pie). En situaciones de crisis matrimonial, la guarda conjunta es entonces el coejercicio de la responsabilidad paterno-filial, pues ambos padres comparten el ejercicio del cuidado del hijo y solo uno de ellos es el cuidador unilateral (bay nota al pie), esto es, su cuidador directo" (lo destacado en cursiva y entre paréntesis es mío).

Otros autores, como Acuña San Martín y Barcia Lehmann, agregarían que el juez, sobre todo debido a la regulación en la $L M C, L T F$ y $C D N$, tiene las herramientas para establecer facultades y derechos para el padre no custodio o repartir funciones entre los padres cuando homologa el acuerdo completo o suficiente de la separación o del divorcio o cuando da lugar a la separación judicial, nulidad o divorcio, mediante sentencia judicial ${ }^{40}$.

\section{Una mala definición de los derechos y facultades de los padres con relación a los hijos}

Sin entrar a analizar todavía la regulación que se genera después de la promulgación de la Reforma del 2013, y a pesar de que en el Derecho chileno la jurisprudencia ha mejorado la forma en que venía asignándose el cuidado personal, el sistema era muy deficiente, por cuanto definía muy mal los derechos de filiación. En otras palabras, el sistema chileno, de acuerdo con lo ya analizado, presentaba deficiencias importantes en cuanto a la forma de estructurar las facultades y derechos de los padres en materia de filiación. Nuestro Derecho, en caso de conflicto, asignaba el cuidado personal, la autoridad parental y la patria potestad a la madre, otorgando al otro solo una limitada relación directa y regular (artículo 229 del CCCb). Así, el TC chileno, que siempre fue renuente a la declaración de inconstitucionalidad del artículo $225.1^{\circ}$ y $3^{\circ}$ del $C C C h$, ante la inminencia de la modificación a las normas precedentes por la Reforma del 2013, terminaría por inclinarse parcialmente a favor de la inaplicabilidad del inciso $3^{\circ}$ de la norma precedente ${ }^{41}$.

En pocas palabras, nuestro Derecho ha desconocido por completo las facultades y derechos del padre no custodio en un sistema de asignación unilateral de derecho de

\footnotetext{
${ }^{40}$ Gómez de la Torre, M., "El nuevo derecho de la niñez", en Estudios de Derecho Privado, Libro Homenaje al profesor Gonzalo Figueroa Yáneez, Editorial Jurídica de Chile, Santiago de Chile, 2008, p. 458 y Lathrop, F., "La custodia alternada o sucesiva de los hijos", en Estudios de Derecho Privado, Libro Homenaje al profesor Gonzalo Figueroa Yáñez, Editorial Jurídica de Chile, Santiago de Chile, 2008, p. 464; Acuña San Martín, M., Efectos jurídicos del divorcio, AbeledoPerrot y Thomson Reuters, Santiago de Chile, 2011, pp. 386 a 392 y Barcia Lehmann, R, Fundamentos del Derecho de Familia e Infancia, Editorial Thomon, 2011, Santiago de Chile, pp. 468 a 504.

41 El fallo del TC resolvió que el exartículo $225.3^{\circ}$ establecía una diferencia de trato que excedía lo que era lícito de hacer para el legislador, según la garantía de igualdad ante la ley.

Ver fallo del TC de 30 de mayo del 2013, en: http://www.tribunalconstitucional.cl/wp/ expedientes? $\mathrm{rol}=2306-12$
} 
filiación. Ello no solo viola el principio del interés superior del niño al sustraer a uno de los padres, sin una causa grave para ello, de casi todas las facultades y derechos de filiación, sino que además infringe los principios de la igualdad ante la ley y de no discriminación. De las amplias categorías de autoridad parental y cuidado personal y de una aplicación razonada del interés superior del niño no se ha dado lugar a un sistema que reconozca los derechos y facultades para el padre no custodio. Esta situación sería modificada por la Reforma del 2013, que a pesar de sus graves deficiencias en torno a los derechos de la infancia, es claramente un avance, si se la compara con la situación anterior.

\section{Incentivos que creó el sistema de filiación antes de la Reforma del 2013, o los incentivos que generó un sistema deficiente de asignación exclusiva de derechos de filiación a la madre}

El sistema chileno incentivó la inhibición de la litigación por parte del padre. Ello se debió a que -a pesar que la Corte Suprema había modificado, como ya vimos, el criterio de asignación del cuidado personal, y aceptaba asignarlo según el interés superior del niño- la asignación al padre se hacía en los casos en que la madre perjudica o daña al niño (es decir, en casos en que perfectamente se podía aplicar los artículos 226 del CCC $b$ y $42, \mathrm{~N}^{\mathrm{o}} 3$ de la $\left.L P M\right)^{42}$. En este sentido, la Corte solo aplica el principio del interés superior como un mecanismo protector de la infancia y no como uno que permite el más adecuado desarrollo del menor. Así, hasta ahora los tribunales no asignan el cuidado personal de acuerdo con las habilidades parentales de los padres, y alguna doctrina era reacia a considerar las habilidades parentales como un criterio de asignación ${ }^{43}$. Sin perjuicio de ello, la evolución de la jurisprudencia ha sido especialmente relevante en cuanto al Derecho de la infancia y todo indicaba que las habilidades parentales, aplicadas según el interés superior del niño, serían tomadas en cuenta como un criterio de asignación del cuidado personal. Por esta razón la regla de la asignación de la "preferencia materna”, como criterio de adjudicación previo privilegiado, tenía sus días contados. Al respecto solo caben dos comentarios. El cambio de sistema de atribución del cuidado personal, según el interés superior del niño, como criterio rector, está de acuerdo

${ }^{42}$ Esta última norma establece que [p]ara los efectos del artículo 226 del Código Civil, se entenderá que uno o ambos padres se encuentran en el caso de inhabilidad física o moral: $3^{\circ}$ Cuando no velaren por la crianza, cuidado personal o educación del hijo.

${ }^{43}$ En este sentido Barrientos señala que “...por su claridad, queremos destacar un fallo de la Corte de Apelaciones de Rancagua, de 30 de diciembre de 2010, que señaló ante esta práctica mayoritaria de tribunales que «No se trata de examinar las competencias parentales, como supone la Sra. Jueza a quo, para compararlas y establecer una diferencia a favor de un padre, cuestión siempre necesariamente subjetiva. Justamente por eso, para alterar la situación fáctica en que los niños están no basta cualquier diferencia; debe haber razones poderosas que indiquen a las claras que su interés superior exige el cambio»”.

Barrientos Zamorano, M., “¿Es interés superior o inferior del niño? Aplicación jurisprudencial del artículo 42 de la Ley de Menores a la luz del Código Civil”, en Estudios de Derecho Civil VII (X Jornadas de Derecho Civil), Viña del Mar, Elorriaga de Bonis, Fabián (coordinador), AbeledoPerrot, Legal Publishing Chile y Thomson Reuters, Santiago de Chile, 2012, p. 125. 
con las modificaciones introducidas a nuestro Derecho por las $L M C$ y $L T F$, la $C D N$, y obedece a la interpretación realizada frente a normas muy similares a la nuestra por el Derecho comparado; pero ello solo es compatible con un sistema que pone en el centro de atención las facultades y derechos del padre no custodio. La forma en que se aplicaba el Derecho violaba gravemente los derechos de la infancia, por cuanto dicha aplicación era incompatible con la $C D N$, que nos obliga a que ambos padres estén presentes en la crianza y educación de sus hijos, independientemente de la ruptura de los padres y de la adopción de un sistema de asignación preferente de cuidado personal a uno de ellos. Este panorama podría modificarse con la promulgación de la Ley No 20.680 .

\section{Referencia a la Reforma al Cuidado Personal en materia de ASIGNACIÓN DE FACULTADES Y DERECHOS DE FILIACIÓN PARA EL PADRE CUSTODIO Y NO CUSTODIO Y A LA LEY N 20.680}

La descripción precedente corresponde al escenario anterior a la Ley $\mathrm{N}^{0} 20.680$, sobre modificaciones al Código Civil y a otros cuerpos legales, con el objeto de proteger la integridad del menor en caso de que sus padres vivan separados, publicada en el Diario Oficial el 21 de junio del 2013. El Congreso aprobó la referida ley, que modifica sustancialmente las facultades y derechos de los padres que no viven juntos, sobre todo respecto del padre no custodio.

El Proyecto de Reforma enviado por el Ejecutivo desarrollaba un sistema de asignación judicial de cuidado personal exclusivo a uno de los padres -haciéndose cargo de la importancia del principio de la igualdad de los padres con relación al interés superior del niño-, de acuerdo con el interés superior del niño. Además, la nueva ley mejoró la situación del padre no custodio mediante una regulación bastante exhaustiva de lo que se entiende por relación directa y regular ${ }^{44} y$, finalmente, agregó la figura de la corresponsabilidad parental en el artículo 224 del CCCh. Al Proyecto se le pueden hacer tres críticas. La primera es que mantenía la regla de la preferencia materna, aunque lo hacía como regla de asignación legal y supletoria, pero afortunadamente, como se verá, esta

${ }^{44}$ El Proyecto se ocupó de las facultades del padre no custodio en los artículos $225.5^{\circ}$, última parte, y 229. De este modo se establece en estas disposiciones lo siguiente: “...[s]iempre que el juez atribuya el cuidado personal del hijo a uno de los padres, deberá establecer, de oficio o a petición de parte, en la misma resolución, la frecuencia y libertad con que el otro mantendrá con él una relación directa, regular y personal.

Art. 229. El padre o madre que no tenga el cuidado personal del hijo no será privado del derecho ni quedará exento del deber que consiste en mantener con él una relación directa, regular y personal, la que se ejercerá con la frecuencia y libertad acordada directamente con quien lo tiene a su cuidado en las convenciones a que se refiere el inciso primero del artículo 225 o, en su defecto, con las que el juez estimare conveniente para el hijo.

Se entiende por relación directa, regular y personal, aquella que propende a que el vínculo paterno filial entre el padre no custodio y su hijo se mantenga a través de un contacto personal, periódico y estable. El régimen variará según la edad del hijo y la relación que exista con el padre no custodio, las circunstancias 
situación se corrigió en el Congreso ${ }^{45}$. La segunda es una crítica tanto al Proyecto como a la ley, por cuanto no se facultó al juez para decretar el cuidado compartido, a solicitud de uno de los padres, con oposición del otro. Este supuesto es ampliamente aceptado en el Derecho comparado, sobre todo en los casos como el chileno, que adoptan un sistema de cuidado personal exclusivo. Y finalmente, es criticable que en el Proyecto y la ley no hayan establecido un cuidado personal compartido como regla de atribución legal supletoria y judicial, como existe en el Derecho comparado.

Las principales modificaciones al sistema de cuidado personal, en caso de que los padres estén separados, son las siguientes:

\section{A. En torno a las facultades y derechos conjuntos}

i) Se establece como principio basal y fundamental la corresponsabilidad de los padres en los siguientes términos: ambos padres, vivan juntos o separados, participarán en forma activa, equitativa y permanente en la crianza y educación de sus hijos (nuevo Art. 224 del $(C C h$ ). Esta es naturalmente una forma de titularidad y ejercicio conjunto de facultades y derechos, que comprenden básicamente todos los aspectos que pertenecen a la crianza y educación de los hijos. De esta forma, la ley reduce el ámbito de aplicación del cuidado personal, sino que exige que los padres se vean activamente involucrados en la crianza y educación de sus hijos en los aspectos cotidianos.

ii) Se consigna una forma reducida de cuidado personal compartido por cuanto solo contempla dicho cuidado de común acuerdo (artículo $225.1^{\circ}$ y $2^{\circ}$ del CCCh), ignorando de esta forma al Derecho comparado.

particulares, necesidades afectivas y otros elementos que deban tomarse en cuenta, siempre en consideración del mejor interés del hijo.

Con todo, sea que se decrete judicialmente el régimen de relación directa, regular y personal o en la aprobación de acuerdos de los padres en estas materias, el juez deberá asegurar la mayor participación y corresponsabilidad de ambos padres en la vida del hijo, estableciendo las condiciones que fomenten una relación paterno filial sana y cercana".

45 El Proyecto enviado por el Ejecutivo al Congreso mantenía la regla de "la preferencia materna", pero solo como un criterio de asignación legal y supletorio, y establecía como criterio de asignación judicial el interés superior del niño. En el Proyecto se señalaba, en los nuevos incisos $4^{\circ}$ y la primera parte del inciso $5^{\circ}$ del artículo 225 del CCCh, que: "[m]ientras no haya acuerdo entre los padres o decisión judicial, a la madre toca el cuidado personal de los hijos menores, sin perjuicio de la relación directa, regular y personal que deberán mantener con el padre.

En cualquiera de los casos establecidos en este artículo, cuando las circunstancias lo requieran y el interés del hijo lo haga conveniente, el juez podrá modificar lo establecido, para atribuir el cuidado personal del hijo al otro de los padres, o radicarlo en uno solo de ellos, si por acuerdo existiere alguna forma de ejercicio compartido". 


\section{B. En cuanto a las facultades y derechos indistintos del padre no custodio}

i) Se desecha como regla de atribución legal supletoria la preferencia materna, optándose por la mantención del cuidado personal a favor del padre que convive con el menor.

ii) La regla de atribución judicial es simplemente, a diferencia de lo establecido en el

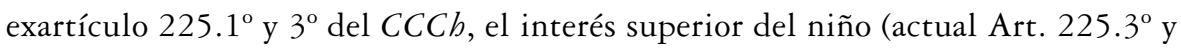
$4^{\circ}$ del $C(C h)$. A este respecto, la ley se ocupó de incorporar al $C C C h$ un artículo 225-2 que establece las circunstancias que debe ponderar el juez al momento de asignar el cuidado personal a uno de los padres ${ }^{46}$.

iii) Esta vez, a diferencia del sistema anterior, y sin perjuicio de las facultades y derechos que se desprenden de la corresponsabilidad, el padre no custodio tiene una serie de facultades y derechos que se desprenden de la relación directa y regular. En este sentido, la ley modificó los artículos $225.6^{\circ}$ y 229 y agregó un artículo 229-2 y concretizó lo que se entiende por relación directa y regular, estableciendo lo siguiente:

“Art. 225.6 Siempre que el juez atribuya el cuidado personal del hijo a uno de los padres, deberá establecer, de oficio o a petición de parte, en la misma resolución, la frecuencia y libertad con que el otro padre o madre que no tiene el cuidado personal mantendrá una relación directa y regular con los hijos, considerando su interés superior, siempre que se cumplan los criterios dispuestos en el artículo 229.

Art. 229. El padre o madre que no tenga el cuidado personal del hijo tendrá el derecho y el deber de mantener con él una relación directa y regular, la que se ejercerá con la frecuencia y libertad acordada directamente con quien lo tiene a su cuidado

${ }^{46}$ De esta forma, la nueva disposición establece lo siguiente:

“Art. 225-2. En el establecimiento del régimen y ejercicio del cuidado personal, se considerarán y ponderarán conjuntamente los siguientes criterios y circunstancias:

a) La vinculación afectiva entre el hijo y sus padres, y demás personas de su entorno familiar.

b) La aptitud de los padres para garantizar el bienestar del hijo y la posibilidad de procurarle un entorno adecuado, según su edad.

c) La contribución a la mantención del hijo mientras estuvo bajo el cuidado personal del otro padre, pudiendo hacerlo.

d) La actitud de cada uno de los padres para cooperar con el otro, a fin de asegurar la máxima estabilidad al hijo y garantizar la relación directa y regular, para lo cual considerará especialmente lo dispuesto en el inciso quinto del artículo 229.

e) La dedicación efectiva que cada uno de los padres procuraba al hijo antes de la separación y, especialmente, la que pueda seguir desarrollando de acuerdo con sus posibilidades.

f) La opinión expresada por el hijo.

g) El resultado de los informes periciales que se haya ordenado practicar.

h) Los acuerdos de los padres antes y durante el respectivo juicio.

i) El domicilio de los padres.

j) Cualquier otro antecedente que sea relevante atendido el interés superior del hijo". 
según las convenciones a que se refiere el inciso primero del artículo 225 o, en su defecto, con las que el juez estimare conveniente para el hijo.

Se entiende por relación directa y regular aquella que propende a que el vínculo familiar entre el padre o madre que no ejerce el cuidado personal y su hijo se mantenga a través de un contacto periódico y estable.

Para la determinación de este régimen, los padres, o el juez en su caso, fomentarán una relación sana y cercana entre el padre o madre que no ejerce el cuidado personal y su hijo, velando por el interés superior de este último, su derecho a ser oído y la evolución de sus facultades, y considerando especialmente:

a) La edad del hijo.

b) La vinculación afectiva entre el hijo y su padre o madre, según corresponda, y la relación con sus parientes cercanos.

c) El régimen de cuidado personal del hijo que se haya acordado o determinado.

d) Cualquier otro elemento de relevancia en consideración al interés superior del hijo.

Sea que se decrete judicialmente el régimen de relación directa y regular o en la aprobación de acuerdos de los padres en estas materias, el juez deberá asegurar la mayor participación y corresponsabilidad de estos en la vida del hijo, estableciendo las condiciones que fomenten una relación sana y cercana.

El padre o madre que ejerza el cuidado personal del hijo no obstaculizará el régimen de relación directa y regular que se establezca a favor del otro padre, conforme a lo preceptuado en este artículo.

Se suspenderá o restringirá el ejercicio de este derecho cuando manifiestamente perjudique el bienestar del hijo, lo que declarará el tribunal fundadamente.

Art. 229-2. El hijo tiene derecho a mantener una relación directa y regular con sus abuelos. A falta de acuerdo, el juez fijará la modalidad de esta relación atendido el interés del hijo, en conformidad a los criterios del artículo 229”.

Naturalmente existen otras importantes reformas en torno a la patria potestad, pero en este trabajo solo se abordan los aspectos personales de la filiación.

\section{Principales conclusiones del presente trabajo}

\section{A. Referencia al sistema anterior a la Reforma del 2013}

i. En del Derecho chileno no se establecían facultades y derechos conjuntos, como en el Derecho comparado. Así, como se analizó, ello sucedía en el Derecho español, mediante figuras como la titularidad y ejercicio de la patria potestad que se contraponía al otorgamiento de la guarda exclusiva; y en los Derechos italiano y alemán. 
ii. En el Derecho chileno, a pesar de establecerse un sistema unilateral o exclusivo de asignación el cuidado personal, no se consignaban facultades y derechos para el padre no custodio, salvo la mantención de una relación directa y regular.

iii. El sistema chileno de infancia no asignaba los derechos y facultades de filiación de acuerdo con el interés superior del niño, y solo se aplicaba este criterio como principio de protección de la infancia. En los casos que se asignaba el cuidado personal de forma exclusiva a la madre, o excepcionalmente al padre, no se respetaban los principios del interés superior del niño, ni de la igualdad de los padres.

iv. En resumen, el sistema recientemente modificado no asigna los derechos de filiación de acuerdo con el principio del interés superior del niño, ni tampoco establecía facultades y derechos para el padre no custodio en los términos que lo hace el Derecho comparado.

v. En consideración a ello nuestro sistema violaba doblemente el principio del interés superior del niño. Lo hacía en torno a su forma de asignación, tanto legal supletoria como judicial, por cuanto prefería a la madre y lo hacía en torno al ejercicio de los derechos de filiación, al no establecer facultades y derechos para el padre no custodio, fuera de una menguada relación directa y regular.

\section{B. Referencia al sistema instaurando por la Reforma del 2013}

i. La Reforma afortunadamente terminó con la regla de la asignación del cuidado personal de forma legal y supletoria a la madre, estableciendo como regla la custodia a favor del padre que conviva con el niño.

ii. La Reforma al inclinarse por un cuidado personal exclusivo a uno de los padres, en caso de conflicto, abre muchas interrogantes; pero, al menos, establece dos mecanismos de compensación para el padre no custodio: el primero es el de la corresponsabilidad, que en el Derecho comparado es una forma de cuidado compartido, y el segundo es la especificación de la relación directa y regular. Naturalmente, existe una inconsistencia en el establecimiento de la corresponsabilidad, como principio rector, y la consagración de un sistema de asignación de cuidado personal exclusivo a uno de los padres. Ello se evidencia de lo señalado en la propia discusión en el Congreso ${ }^{47}$. A este respecto el ámbito de aplicación de la corresponsabilidad nos indica que las facultades y derechos que se desprenden de la crianza y educación son siempre conjuntos y que el ámbito del cuidado personal se debería reducir sustancialmente después de entrada en vigencia la ley. A dicha

${ }^{47}$ En la historia fidedigna de la ley, la magistrada Negroni, haciendo referencia a los autores trasandinos Andrés Gil Domínguez, María Victoria Fama y Marisa Herrera, señaló que la corresponsabilidad consiste en "reconocer a ambos padres el derecho a tomar las decisiones y distribuir equitativamente las responsabilidades y derechos inherentes al ejercicio de la responsabilidad parental, según sus distintas funciones, recursos, posibilidades y características personales (hay nota al pie)" (lo señalado entre paréntesis es mío).

Ver: "Historia de la Ley No 20.680. Introduce modificaciones al Código Civil y a otros cuerpos legales, con el objeto de proteger la integridad del menor en caso de que sus padres vivan separados", en Biblioteca del Congreso (http://www.leychile.cl/Consulta/portada_hl?tipo_norma=XX1\&nro_ley=20680\&anio=2013), p. 43. 
reducción también contribuye la delimitación del contenido de la relación directa y regular. Esta parece ser la única conclusión a la que se puede arribar para hacer los principios de igualdad de los padres e interés superior del niño concurrentes. Pero la aplicación que de este trabajo se sugiere, de la corresponsabilidad -como una forma parcial de cuidado compartido conjunto respecto de las facultades y derechos de crianza y educación-, disiparían las dudas que la reforma produjo en algunos especialistas ${ }^{48}$. Así, los niños deberán permanecer o estar en contacto con ambos padres, independientemente de la asignación del cuidado personal que pudiere hacerse a uno de ellos, respecto de su crianza y educación. Los jueces entones deberán establecer que el niño esté por ejemplo dos horas al día con el padre no custodio para los efectos de su educación (para que haga las tareas con él), un par de días a la semana para su esparcimiento (como si el padre no custodio lleva al niño a hacer deportes o clases de religión), que lo cuide cuando esté enfermo, etcétera.

iii. Esta forma de comprender la corresponsabilidad nos permitiría que -aunque los derechos de filiación no se asignen de forma igualitaria a los padres, como sugiere el Derecho comparado, violándose de esta forma el principio del interés superior del niño-, en el ejercicio de las facultades y derechos de los padres, se respeten ambos principios (interés superior del niño e igualdad de los padres).

\section{BIBLIOGRAFÍA}

Acuña San Martín, M., Efectos jurídicos del divorcio, AbeledoPerrot y Thomson Reuters, Santiago de Chile, 2011.

Albaladejo García, M., Comentarios al Código Civil y Compilaciones Forales, M. Albaladejo García (Editor), tomos VIII, vol. $2^{\circ}$ (artículos 618 a 656) y X, vol. X (artículos 774 a 805), editoriales Revista de Derecho Privado, 1986 y 1984.

Barcia Lehmann, R., "Una Mirada al Cuidado Personal, y en especial a los artículos 224, 225.1 y $3^{\circ}$ del Código Civil y 42 de la Ley de Protección de Menores, desde la perspectiva del Interés superior del Niño", en Estudios de Derecho Civil VII (X Jornadas de Derecho Civil),

${ }^{48}$ En este sentido se puede consultar a Fabiola Lathrop, profesora e investigadora en Derecho de Familia, y Andrés Donoso Castillo, Médico Psiquiatra, Terapeuta Familiar del Instituto Chileno de Terapia Familiar. Lathrop, a este respecto, señala que "el problema que observa en esta modificación es que si esta declaración de corresponsabilidad no se traduce en instrumentos concretos, corre el riesgo de volverse en letra muerta”. Y Andrés Donoso agrega que “...el modelo coparental o de Custodia Compartida, se basa en la idea fuerza, que el mejor padre, son ambos padres y se erige como una propuesta posquiebre vinculativo y responde esencialmente al Principio del Interés Superior del Niño. Cambia el término de custodia exclusiva, por la tuición compartida con sistema de alternancia física legal conjunta, lo que en su parecer, debe ser normado jurídicamente y plasmado en el marco de la tuición compartida, aspecto que le conferirá la fuerza del derecho, de lo contrario nos posicionaría frente a una utopía”.

Ver: "Historia de la Ley $\mathrm{N}^{\circ}$ 20.680. Introduce modificaciones al Código Civil y a otros cuerpos legales, con el objeto de proteger la integridad del menor en caso de que sus padres vivan separados", en Biblioteca del Congreso (http://www.leychile.cl/Consulta/portada_hl?tipo_norma=XX1\&nro_ley=20680\&anio=2013), pp. 50 y 61 . 
Viña del Mar, Elorriaga de Bonis, Fabián (coordinador), AbeledoPerrot, Legal Publishing Chile y Thomson Reuters, Santiago de Chile, 2012.

Barcia Lehmann, R., Fundamentos del Derecho de Familia e Infancia, Editorial Thomon, 2011, Santiago de Chile.

Barral Viñals, I., "La Potestad del Padre y de la Madre", Capítulo 18, Derecho de Familia, en Maluquer de Motes (coord.), Carlos, Derecho de Familia, Bosch, Barcelona, 2000.

Barrientos Zamorano, M., “¿Es interés superior o inferior del niño. Aplicación jurisprudencial del artículo 42 de la Ley de Menores a la luz del Código Civil”, en Estudios de Derecho Civil VII (X Jornadas de Derecho Civil), Viña del Mar, Elorriaga de Bonis, Fabián (coordinador), AbeledoPerrot, Legal Publishing Chile y Thomson Reuters, Santiago de Chile, 2012.

Bevan, H. K., Child Law, Butterworths, London, 1989.

CASTÁN VÁsquez, J.M., "La patria potestad sobre los hijos nacidos fuera del matrimonio", en Revista de Derecho Privado, 1987.

Castán VÁsquez, J.M., "Comentario del artículo 156 del Código Civil”, en Comentarios al Código Civil y Compilaciones Forales, Edersa, Madrid, 1982, tomo IV.

Castán VÁsquez, J.M., "Comentarios a los artículos 154 a 170 del C.c.”, en Comentarios al Código Civil y Compilaciones Forales, Albaladejo García, M., Editorial Revista de Derecho Privado, tomo III, vol. 2 ${ }^{\circ}$ Editoriales Revista de Derecho Privado, 1982.

Castán VÁsquez, J.M., "El Problema de Ejercicio de la Patria Potestad por Padres Menores en el Derecho Argentino y en el Derecho Español”, en Revista de Derecho Privado, Editorial Revista de Derecho Privado, Madrid, 1982.

Castán Vásquez, J.M., "La Llamada 'Patria Potestad de Hecho”, en Revista de Derecho Privado, Julio-Agosto de 1978, editorial Revista de Derecho Privado, Madrid.

Castán VÁsquez, J.M., "La Patria Potestad sobre los Hijos Nacidos fuera de Matrimonio", en Revista de Derecho Privado, febrero de 1987, editorial Revista de Derecho Privado, Madrid.

Castán Vásquez, J.M., La Patria Potestad, editorial Revistas de Derecho Privado, Madrid, 1960.

Castillo Martínez, C. C., La Privación de la Patria Potestad, editorial Práctica del Derecho, Valencia, 2000.

Cretney, S. M., Principles of Family Law, London Sweet \& Maxwell, Londres, 1984, p. 401.

De la Cámara Álvarez, M., "El Nuevo Régimen Jurídico de la Filiación”, en La Reforma del Derecho de Familia, Matrimonio, Separación, Divorcio, Régimen Económico Matrimonial, Filiación y Patria Potestad, Jornadas Hispalenses sobre la Reforma del Derecho de Familia, Imprenta Sevilla S.A., 1982.

De la Haza Díaz, P., “Notas sobre el 'Affidamento’ Familiar en el Derecho Italiano y el Acogimiento Familiar en el Código Civil Español”, en Revista General de Legislación y Jurisprudencia, año CXXXVI, núm. 3, Tomo XCV, Editorial Reus, Madrid, septiembre de 1987.

De la Valgóma, M., "Notas sobre la Titularidad en el Ejercicio de la Patria Potestad", en Revista de la Facultad de Derecho de la Universidad Complutense, Primavera, 1981, núm. 62, Artes Gráficas Benzal, Madrid.

De Prada González, J.M., "La Patria Potestad tras la Reforma del Código Civil", en Anales de la Academia Matrisense del Notariado, Tomo XXV, Estudios sobre el Nuevo Derecho de Familia y Sucesiones, Editorial Revista de Derecho Privado, 1982.

Del Vas GonZález, J.M., "Rottura della famiglia e interesse dei figli en el Derecho Civil italiano" en Revista Crítica de Derecho Inmobiliario, núm. 717, 2010.

Díaz Alabart, S., "Comentarios a los Artículos 236-238", en Comentarios a la Reforma de Nacionalidad y Tutela, Tecnos, 1986.

Díez-Picazo, L., "La Reforma del Código Civil en Materia de Patria Potestad", en La Reforma del Derecho de Familia, Matrimonio, Separación, Divorcio, Régimen Económico Matrimonial, Filiación 
y Patria Potestad, Jornadas Hispalenses sobre la Reforma del Derecho de Familia, Imprenta Sevilla S.A., 1982.

Díez-Picazo, L., "Notas sobre la Reforma del Código Civil en Materia de Patria Potestad", en Anuario de Derecho Civil, Tomo XXXV, Fascículo I, enero-marzo, 1982, Artes Gráficas y Ediciones, Madrid.

García Cantero, G., Las relaciones familiares entre nietos y abuelos según la Ley de 21 de noviembre de 2003, Thomson Civitas, Cuadernos Civitas, Madrid, España, 2004.

Gómez de la Torre, M., "El nuevo derecho de la niñez", en Estudios de Derecho Privado, Libro Homenaje al profesor Gonzalo Figueroa Yáñez, Editorial Jurídica de Chile, Santiago de Chile, 2008.

Historia de la Ley. Compilación de la Biblioteca del Congreso Nacional, Santiago, año 2000, Volumen II.

Lathrop Gómez, F., “(In)constitucionalidad de la regla de atribución preferente materna del cuidado personal de los hijos del artículo 225 del Código Civil chileno", en Revista Ius et Praxis, Año 16, núm. 2, 2010.

Lathrop Gómez, F., Custodia compartida de los hijos, La Ley, Madrid, España, 2008.

Lathrop Gómez, F., "La custodia alternada o sucesiva de los hijos", en Estudios de Derecho Privado, Libro Homenaje al profesor Gonzalo Figueroa Yáñez, Editorial Jurídica de Chile, Santiago de Chile, 2008.

Linacero de la Fuente, M.A., "Custodia de Menores. Conflicto entre el Padre y los Abuelos", en Revista del Poder Judicial, núm. 30, junio, 1993, Publicaciones del Poder Judicial.

Linacero de la Fuente, M.A., Régimen Patrimonial de la Patria Potestad, Editorial Montecorvo, S.A., Madrid, 1990.

López Pérez, J., Prórroga y Rehabilitación de la Patria Potestad, Bosch Editorial, S.A., Barcelona, 1992.

López Pérez, M. del C., La Patria Potestad del Titular, Publicaciones de la Universidad de Valladolid, 1982.

Magaz Sangro, C., "La Acomodación de los Acuerdos, Medidas o Efectos a Otras Circunstancias", en Revista Jurídica General, Boletín del Ilustre Colegio de Abogados de Madrid, núm. 8, $3^{\text {a }}$ Época, noviembre de 1997.

Martín-Granizo Fernández, M., "La Patria Potestad Prorrogada y la Rehabilitación después de su Reforma por la ley 13/1984, de 24 de octubre", Revista de Legislación y Jurisprudencia, Año CXXXIV, junio, 1985, núm. 6, segunda época, Tomo XC (258 de la Colección), Editorial Reus.

Mizrahi, M.L., Familia, matrimonio y divorcio, Editorial Astrea, Argentina, 2006.

Pau Pedrón, A., "La Nueva Regulación Alemana sobre la Patria Potestad", en Anuario de Derecho Civil, Tomo XXXV, Fascículo III, Julio-Septiembre, Artes Gráficas y Ediciones, Madrid, 1982.

Rivero Hernández, F., "La Guarda y Custodia de los Hijos y Derechos de Visita tras las Crisis Matrimonial”, en Cevilla Grarzón, M. D. (coord.), IV Seminario de Estudios Jurídicos y Criminológicos, Servicio de Publicaciones de la Universidad de Cádiz, 1996.

Rivero Hernández, F., "Las Relaciones Paterno-Filiales (Título, Ejercicio y Contenido de la Patria Potestad, Guarda y Cuidados y Régimen de Visitas) como Contenido del Convenio Regulador", en Convenios Reguladores de las Crisis Matrimoniales, Instituto de Ciencias para la Familia, Ediciones Universidad de Navarra S.A., Pamplona, 1989.

Rivero Hernández, F., en Álbacar López, J.L., "Comentarios del Código Civil”, tomo I, Centro de Publicaciones, Madrid, 1991.

Romero Girón, J., "Patria Potestad", en Revista del Ilustre Colegio Notarial de Granada, Academia Granadina del Notariado, núm. 63, marzo 1986, Sección Tercera. 
Roppo, V., Istituzione Di Diritto, Monduzzi editore, 1996.

Sancho Rebullida, F. de A., "Título V. De la Patria Potestad y de la Filiación”, en Albaladejo García, M. Editorial Revista de Derecho Privado, Comentarios al Código Civil y Compilaciones Forales, Tomo XXXVI, vol. $1^{\circ}$, Leyes 42 a 81, Compilación del Fuero de Navarra, Editorial de Derecho Reunidas, Madrid, 1990.

Terré, F. y Fenouillet, D., Droit civil. Les Personnes. La Famille. Les Incapacités, $7^{\mathrm{a}}$ édition, Dalloz, 2005.

Zannoni, E., Derecho de Familia, Editorial Astrea, Tomo I, 1981.

Zarraluqui Navarro, E., Guarda y custodia vs. patria potestad en cuanto a la residencia de los bijos menores, Derecho de Familia, Novedades en dos perspectivas, Asociación Española de Abogados de Familia, Dykinson, Madrid, España, 2010.

\section{Sitios visitados}

http://papers.ssrn.com/sol3/papers.cfm?abstract_id=1300391

http://www.senado.cl/appsenado/templates/tramitacion/index.php http://www.camera.it/parlam/ leggi/060541.htm

http://www.thetimes.co.uk/tto/news/uk/article1950995.ece

http://www.bverfg.de/entscheidungen/rs20100721_1bvr042009en.html

http://www.bverfg.de/entscheidungen/rs20100721_1bvr042009.html

http://www.tribunalconstitucional.cl/index.php/sentencias/download/pdf/1272

\section{Normas citadas}

Bürgerliches Gesetzbuch [Código Civil alemán].

Código Civil chileno.

Código Civil español.

Code [Código Civil francés].

Codice Civile [Código Civil italiano de1942].

Constitución Política de la República de Chile.

Convención de Naciones Unidas sobre Derechos del Niño.

Children Act de 1989.

Ley de Filiación [Ley No 19.585/1998].

Ley de Matrimonio Civil [Ley No 19.947/2004].

Ley de Tribunales de Familia [Ley No $\mathrm{N}^{\circ}$ 19.968/2004].

Ley de Protección de Menores [Ley No 16.618/2000].

Ley $\mathrm{N}^{\circ} 5.521$ de 1934 ..

Ley $\mathrm{N}^{\circ} 10.271$ de 1952.

Ley $\mathrm{N}^{\circ} 18.802$. 
